\title{
Optical Emission Study of Nonthermal Plasma Confirms Reaction Mechanisms Involving Neutral Rather than Charged Species
}

\author{
Morris D. Argyle \\ mdargyle@byu.edu \\ Gui-Bing Zhao \\ Maciej Radosz
}

Follow this and additional works at: https://scholarsarchive.byu.edu/facpub

Part of the Chemical Engineering Commons

\section{Original Publication Citation}

G.B. Zhao, M.D. Argyle, M. Radosz, "Optical Emission Study of Nonthermal Plasma Confirms Reaction Mechanisms Involving Neutral Rather than Charged Species." Journal of Applied Physics, 11, 3333/1-3333/14, 27. http://jap.aip.org/resource/1/japiau/v11/i3/p3333_s1

\section{BYU ScholarsArchive Citation}

Argyle, Morris D.; Zhao, Gui-Bing; and Radosz, Maciej, "Optical Emission Study of Nonthermal Plasma Confirms Reaction Mechanisms Involving Neutral Rather than Charged Species" (2006). Faculty Publications. 288.

https://scholarsarchive.byu.edu/facpub/288 


\title{
Optical emission study of nonthermal plasma confirms reaction mechanisms involving neutral rather than charged species
}

\author{
Gui-Bing Zhao, ${ }^{\text {a) }}$ Morris D. Argyle, ${ }^{\text {b) }}$ and Maciej Radosz ${ }^{\mathrm{c})}$ \\ Department of Chemical and Petroleum Engineering, University of Wyoming, \\ Laramie, Wyoming 82071-3295
}

(Received 15 November 2005; accepted 4 December 2006; published online 6 February 2007)

\begin{abstract}
Charge transfer reactions are commonly used to explain $\mathrm{NO}_{x}$ conversion in nonthermal plasma. An analysis of optical emission spectra induced by pulsed corona discharge in $\mathrm{NO}_{x}$-containing argon suggests that, in fact, the contribution of charge transfer reactions to $\mathrm{NO}_{x}$ conversion in nonthermal plasma is negligible. During electrical discharge in such gas mixtures, $\mathrm{NO}(B)$, an electronic excited state of $\mathrm{NO}$ formed due to the dissociative recombination reactions of $\mathrm{NO}_{2}{ }^{+}$and $\mathrm{N}_{2} \mathrm{O}^{+}$and the optical emission of $\mathrm{NO}(B)$ could be a proof that cations are responsible for $\mathrm{NO}_{x}$ conversion. However, the optical emission of $\mathrm{NO}(B)$ is not observed, leading to the conclusion that cations are not involved to any measurable degree. Therefore, charge transfer reactions cannot play a significant role in nonthermal plasma largely because the cations are neutralized with electrons before any charge transfer reactions can occur and concentrations of radicals are far higher than those of cations, which inhibits charged particle reactions. Instead, neutral active species, such as atoms, molecular fragments, and excited molecules, are the major active species contributing to nonthermal plasma reactions. (C) 2007 American Institute of Physics. [DOI: 10.1063/1.2434002]
\end{abstract}

\section{INTRODUCTION}

Short-duration high-voltage pulses in a wire-cylinder reactor produce nonhomogeneous electric fields that induce nonthermal plasma used for conversion of nitrogen oxides $\left(\mathrm{NO}_{x}\right)$. When the wire electrode is positively charged, the induced plasma channels are positive streamers that propagate from the wire anode to the cylinder cathode; the discharge pulse itself is then called a positive corona discharge. The pulse duration of the corona discharge is less than $100 \mathrm{~ns},{ }^{1-3}$ and is defined as the pulse-on period. The energetic electrons in the streamer excite gas molecules and produce three kinds of chemically active species, metastable excited states, radicals, and cations, through the following reactions:

$$
\text { molecular excitation } e+A B \rightarrow A B^{*}+e \text {, }
$$

molecular dissociation $e+A B \rightarrow A+B+e$,

$$
\text { ionization } e+A B \rightarrow A B^{+}+2 e,
$$

where the asterisk denotes an excited molecule. These active species contribute to the conversion of nitrogen oxides in between discharge pulses (the pulse-off periods).

The ions produced from (3) mainly react with molecules through charge transfer reactions, for example,

\footnotetext{
${ }^{a)}$ Present address: Blacklight Power Inc., 493 Old Trenton Road, Cranbury, NJ 08536; electronic mail: zhaoguibing@hotmail.com

${ }^{b)}$ Electronic mail: mdargyle@uwyo.edu

${ }^{c)}$ Electronic mail: radosz@uwyo.edu
}

$$
A B^{+}+C D \rightarrow A B+C D^{+}
$$

The cations $C D^{+}$formed from charge transfer reactions can be dissociated through dissociative recombination reactions with electrons

$$
C D^{+}+e \rightarrow C+D .
$$

Extensive experimental and theoretical work ${ }^{4-6}$ has shown that the rate constant of dissociative recombination reaction (5) is at least on the order of $10^{17} \mathrm{~cm}^{3} \mathrm{~mol}^{-1} \mathrm{~s}^{-1}$, which is more than three orders of magnitude higher than the rate constants of radical reactions and reactions of neutral species in electronic excited states, that is, about $10^{14} \mathrm{~cm}^{3} \mathrm{~mol}^{-1} \mathrm{~s}^{-1}$, based on the kinetic limit of these active species at room temperature. Therefore, $\mathrm{NO}_{x}$ may be converted through two reaction pathways: (I) charge transfer reaction (4) and subsequent dissociative recombination (5) involving positive ions and (II) reaction with neutral active species, including atoms, molecular fragments, and excited molecules, which are produced from direct electron collision reactions (1) and (2).

The contribution of ions to $\mathrm{NO}_{x}$ conversion has been debated in the literature. For example, $\mathrm{Chang}^{7}$ compared the rate constants of charge transfer reactions and radical reactions and found that the probabilities of charge transfer reactions are a few orders of magnitude larger than radical reactions. He concluded that charge transfer reactions (path I) play an important role in the $\mathrm{NO}_{x}$ decomposition processes. In contrast, on the basis of abundant experimental and theoretical experience, Kogelschatz ${ }^{8}$ proposed that charged particle reactions are negligible in nonthermal plasmas at atmospheric pressure and that neutral active species, such as atoms, molecular fragments, and excited molecules, are the major active species contributing to nonthermal plasma reactions (path II). van Veldhuizen et al. ${ }^{9}$ analyzed the relative 
importance of ions and radicals for $\mathrm{NO}$ conversion in a pulsed corona reactor and concluded that the ion contribution to NO conversion (path I) is approximately $10 \%-20 \%$ of the radical contribution (path II). However, their theoretical calculation of NO conversion based on this conclusion was 10100 times lower than the experimentally observed values. Recently, $\mathrm{Hu}$ et al. ${ }^{10}$ proposed that cations $\mathrm{N}_{2}{ }^{+}$and atomic $\mathrm{N}$ radicals are responsible for $\mathrm{NO}_{x}\left(\mathrm{NO}, \mathrm{NO}_{2}\right.$, and $\left.\mathrm{N}_{2} \mathrm{O}\right)$ conversion in nonthermal $\mathrm{N}_{2}$ plasma. However, this reaction mechanism was unable to account for byproduct concentrations as a function of power input, e.g., $\mathrm{N}_{2} \mathrm{O}$ in reactant mixtures of $\mathrm{NO}$ and $\mathrm{N}_{2}$ or $\mathrm{NO}$ in reactant mixtures of $\mathrm{NO}_{2}$ and $\mathrm{N}_{2}$. Later, Zhao et al. ${ }^{11,12}$ found that only two active species, $\mathrm{N}_{2}\left(A^{3} \Sigma_{u}{ }^{+}\right)$, which is the first electronic excited state of molecular $\mathrm{N}_{2}$, and $\mathrm{N}$ radicals, are responsible for $\mathrm{NO}_{x}$ conversion in nonthermal $\mathrm{N}_{2}$ plasma and that $\mathrm{N}_{2}{ }^{+}$is not involved. Using a reaction mechanism that includes only $\mathrm{N}_{2}\left(A^{3} \Sigma_{u}{ }^{+}\right)$and $\mathrm{N}$ radicals, while excluding cations such as $\mathrm{N}_{2}{ }^{+}$, Zhao et al. ${ }^{11,12}$ predicted all experimental data in the paper of $\mathrm{Hu}$ et al. ${ }^{10}$ which further confirms that $\mathrm{N}_{2}{ }^{+}$does not contribute to $\mathrm{NO}_{x}$ conversion. A similar reaction mechanism involving only the neutral active species can also predict the effect of $\mathrm{CO}, \mathrm{O}_{2}$, and $\mathrm{CO}_{2}$ on $\mathrm{NO}_{x}$ conversion in nonthermal nitrogen plasmas. ${ }^{11,13-15}$ More recently, however, Hu et al. ${ }^{1}$ proposed that $\mathrm{Ar}^{+}$is the only active species responsible for $\mathrm{NO}_{x}$ conversion in low (ppm) concentrations of $\mathrm{NO}_{x}$ in $\mathrm{Ar}$, but was unable to demonstrate that such a reaction mechanism can predict the effect of $\mathrm{CO}$ on $\mathrm{NO}_{x}$ conversion in nonthermal Ar plasma.

Although the reaction mechanism involving ions could not explain the experimental results, no reports with direct experimental evidence exclude the contribution of ions. The products of dissociative recombination reaction (5) depend on the reactant ions. For atomic ions such as $\mathrm{Ar}^{+}$, electronion reaction produces both ground state argon atoms $(\sim 65 \%)$ and metastable atomic excited states $(\sim 35 \%) .{ }^{16}$ For diatomic ions, the main products of electron-ion reactions are dissociated atoms and atomic excited states. ${ }^{6}$ For example, $\mathrm{NO}^{+}$is dissociated by electrons into ground state atomic $\mathrm{O}$ and $\mathrm{N}$ and excited state $\mathrm{N}\left({ }^{2} D\right) ;{ }^{17,18} \mathrm{~N}_{2}{ }^{+}$is dissociated into ground state $\mathrm{N}$ and excited states $\mathrm{N}\left({ }^{2} D\right)$ and $\mathrm{N}\left({ }^{2} P\right) ;^{19,20}$ and $\mathrm{O}_{2}{ }^{+}$is dissociated into ground state $\mathrm{O}$ and excited states $\mathrm{O}\left({ }^{1} D\right)$ and $\mathrm{O}\left({ }^{1} S\right) \cdot{ }^{21,22}$ For polyatomic ions, the main products of electron-ion reaction are dissociated atoms, polyatomic radicals, molecules, and their excited states. ${ }^{4}$ Others ${ }^{23,24}$ found that $\mathrm{NO}_{2}^{+}$and $\mathrm{N}_{2} \mathrm{O}^{+}$can be dissociated into the excited states of $\mathrm{NO}$ such as $\mathrm{NO}(B)$ and $\mathrm{NO}(A)$ by dissociative recombination reactions with electrons. Therefore, almost all cations can be dissociated into atomic or molecular excited states, which can emit photons through radiative emission to their respective ground state, if these excited states have short enough natural radiative lifetimes. For example, the optical emissions of $\mathrm{N}\left({ }^{2} D\right), \mathrm{N}\left({ }^{2} P\right), \mathrm{O}\left({ }^{1} D\right)$, and $\mathrm{O}\left({ }^{1} S\right)$ are not observed at atmospheric pressure because their natural radiative lifetimes are longer than $0.7 \mathrm{~s} .{ }^{25} \mathrm{How}-$ ever, the optical emission of $\mathrm{NO}(B)$ and $\mathrm{NO}(A)$ can be observed because their natural radiative lifetimes are short enough $(<2 \mu \mathrm{s}) .^{26,27}$ These facts led us to explore the importance of charge transfer reactions in nonthermal plasma using optical emission measurements. The optical emission of $\mathrm{NO}(B)$ and $\mathrm{NO}(A)$ resulting from dissociative recombination reactions of $\mathrm{NO}_{2}{ }^{+}$and $\mathrm{N}_{2} \mathrm{O}^{+}$should be observable if charge transfer reactions are important for $\mathrm{NO}_{x}$ conversion in nonthermal plasma (path I).

The goal of this work is to evaluate the importance of ionic reactions (mainly charge transfer reactions) in nonthermal plasma with argon as a background gas by optical emission measurements. Although most $\mathrm{NO}_{x}$ containing gases are combustion exhaust gases that contain predominantly nitrogen, oxygen, water, and $\mathrm{CO}_{2},{ }^{9,28}$ argon is chosen as a background gas for two reasons. First, argon has a very low dielectric strength (0.18) that is just higher than that of helium $(0.15)$, which has the lowest dielectric strength of any gas. ${ }^{29}$ This implies that argon is one of the most easily ionized species in nonthermal plasma. Although the first ionization energy of argon $(15.76 \mathrm{eV})$ is larger than most diatomic and polyatomic molecules, including $\mathrm{N}_{2}(15.58 \mathrm{eV}), \mathrm{O}_{2}$ (12.06 eV), NO (9.25 eV), $\mathrm{CO}_{2}(13.77 \mathrm{eV}), \mathrm{NO}_{2}(9.79 \mathrm{eV})$, and $\mathrm{N}_{2} \mathrm{O}(12.89 \mathrm{eV}),{ }^{30}$ the rotational and vibrational degrees of freedom offered by diatomic and polyatomic molecules effectively deactivate energetic electrons within one mean free path length, resulting in greater energy dissipation compared to monoatomic gases. ${ }^{31}$ Therefore, in the same electric field, electrons can build up more energy in argon than in diatomic and polyatomic gases because the electrons do not lose as much energy during elastic collisions with neutral argon. The higher energy electrons that form in argon plasma then ionize argon to a greater degree compared to other diatomic and polyatomic molecules under similar reaction conditions. If ionic reactions in argon nonthermal plasmas are shown to be unimportant, the ion concentrations in other gases are expected to be even lower and result in similarly negligible ionic reactions. Therefore, argon should provide general results. The second reason for selecting argon is the simplicity of the analysis. The active species formed from electron collision reactions with argon are relatively simple because no molecular dissociation reaction (2) occurs. Since molecular argon species, such as $\mathrm{Ar}_{2}{ }^{+}$, are not formed from direct electron collision reactions, ${ }^{32}$ the only possible active species are $\mathrm{Ar}^{+}$and the excited atomic states of argon.

\section{EXPERIMENTAL SECTION}

Figure 1 shows the experimental setup. A similar pulsed corona discharge reactor (PCDR) has been described in detail previously. $2,3,11-15,33$ In brief overview, the PCDR consists of a high-voltage power supply, control unit, and pulser/ reactor assembly. The high-voltage supply controls the pulsed power delivered to the reactor. The pulser/reactor assembly contains the pulsed power generator and the pulsed corona discharge reaction chambers. These two subassemblies are connected by a high-voltage cable for charging the capacitors in the pulsed power system and by high-pressure gas lines for controlling the voltage delivered to the reactor. Electrical and switch gas supplies are connected to the control unit; the reactor gas supply and exhaust lines are connected directly to the reactor. The reactor, consisting of two parallel reaction tubes, is fitted with UV-grade quartz win- 


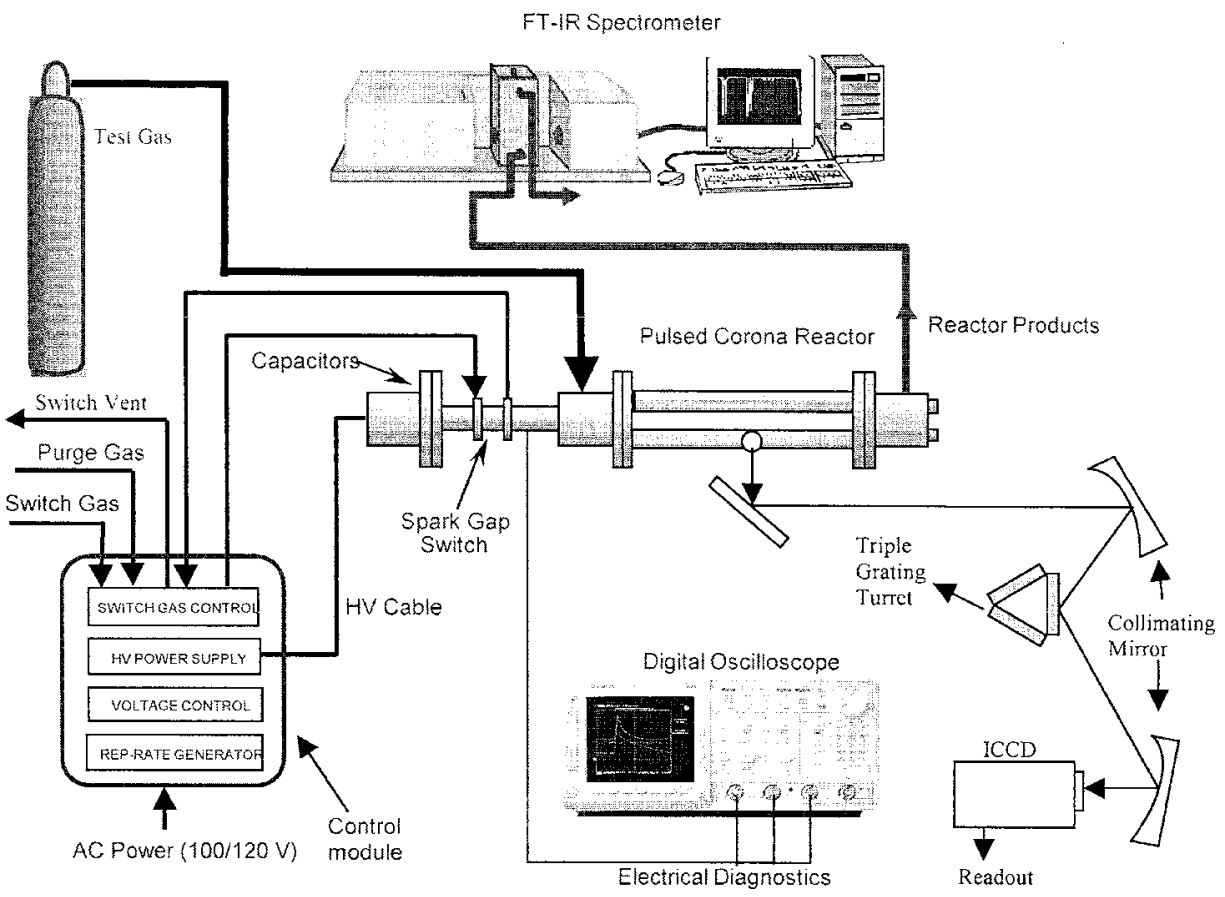

FIG. 1. Experimental setup.

dows for diagnostics and plasma observation. The stainless steel wire has a diameter of $0.58 \mathrm{~mm}$ and each tube is $93 \mathrm{~cm}$ long and $2.3 \mathrm{~cm}$ in diameter. The design permits variation and measurement of the applied voltage and its frequency, reactor current, and voltage, and discharge power and energy. The energy delivered to the reactor per pulse can be calculated from $\frac{1}{2} C V_{c}^{2}$, where $\mathrm{C}$ is the pulse forming capacitance $(800 \mathrm{pF})$ and $V_{c}$ is the constant charge voltage before discharge. The power consumed, $W\left(\mathrm{~J} \mathrm{~s}^{-1}\right)$, is calculated as the product of the input energy per pulse and the pulse frequency.

Plasma-induced optical emissions are observed through the quartz window located $49 \mathrm{~cm}$ from the reactor inlet and are imaged onto the entrance slit of a $0.3 \mathrm{~m}$ focal length monochromator (SpctraPro-300i model). This monochromator includes a triple grating turret for 1, 2, or 3 gratings, an imaging optical system, 32 bit microprocessor controlled scanning, and micrometer controlled entrance slit. An intensified charge coupled device (ICCD) camera with a detection range of 220 to $1000 \mathrm{~nm}$ is mounted on the spectrometer to detect luminescence. The exposure time, entrance-slit width of the spectrometer (10 $\mu \mathrm{m}$ for these experiments), and camera gain were carefully manipulated to obtain the data.

The experimental test matrix is shown in Table I. The four reactant gas mixtures shown in Table I, including ultrahigh purity (UHP) 99.999\% Ar, 290 ppm $\mathrm{N}_{2} \mathrm{O}$ in UHP Ar, 566 ppm NO in UHP Ar, and 408 ppm $\mathrm{N}_{2} \mathrm{O}$ in UHP $\mathrm{N}_{2}$, are used as obtained from the manufacturer (US Airgas). The test

TABLE I. Experimental matrix.

\begin{tabular}{ccc}
\hline \hline System & Flow rate $\left(\mathrm{m}^{3} \mathrm{~s}^{-1}\right)$ & Pressure $(\mathrm{kPa})$ \\
\hline UHP Ar & $1.98 \times 10^{-4}$ & 141 \\
$290 \mathrm{ppm} \mathrm{N} \mathrm{O}_{2}$ in $\mathrm{Ar}$ & $1.98 \times 10^{-4}$ & 141 \\
$566 \mathrm{ppm} \mathrm{NO}$ in $\mathrm{Ar}$ & $1.98 \times 10^{-4}$ & 141 \\
$408 \mathrm{ppm} \mathrm{N} \mathrm{O}_{2}$ in $\mathrm{N}_{2}$ & $1.98 \times 10^{-4}$ & 141 \\
\hline \hline
\end{tabular}

gas mixture is introduced into the PCDR at ambient temperature, around $300 \mathrm{~K}$, and at a flow rate of $1.98 \times 10^{-4} \mathrm{~m}^{3} \mathrm{~s}^{-1}$ (at the reactor inlet conditions). The PCDR pressure is maintained at $141 \mathrm{kPa}$ by control valves on the outlet gas lines. Feed and reactor effluent samples are captured in small stainless steel cylinders and analyzed using a Spectrum 2000 Perkin Elmer Fourier transform infrared (FTIR) spectrometer with a narrow band mercury cadmium telluride (MCT) detector. All experimental data are reproducible within a $\pm 10 \%$ error limit including the FTIR and flow measurement uncertainties.

\section{RESULTS AND DISCUSSION}

\section{A. Optical emission}

Excited active molecules (e.g., $A B^{*}$ ) can return to lower excited energy levels or ground states through two processes:

(1) natural radiation of light, which sometimes produces optical emission (fluorescence) as excited electrons return to lower energy levels,

$$
A B^{*} \rightarrow A B+h \nu, \quad R_{0}=k_{0} C_{A B^{*}},
$$

(2) quenching by interaction with other atoms or molecules,

$$
A B^{*}+C D \rightarrow \text { products, } \quad R_{q}=k_{q} C_{A B^{*}} C_{C D} .
$$

(6) and (7) are parallel reactions. In these chemical equations, $k_{0}$ and $k_{q}$ are the rate constants of natural radiation and quenching, respectively, $C$ is the mole concentration of the respective species, and $R$ is the reaction rate. The rate constant of natural radiation is inversely proportional to the natural lifetime of the excited molecules. If there are $n$ kinds of molecules in the gas mixture which can quench $A B^{*}$, the selectivity of natural radiation, $S_{0}$, can be defined as 


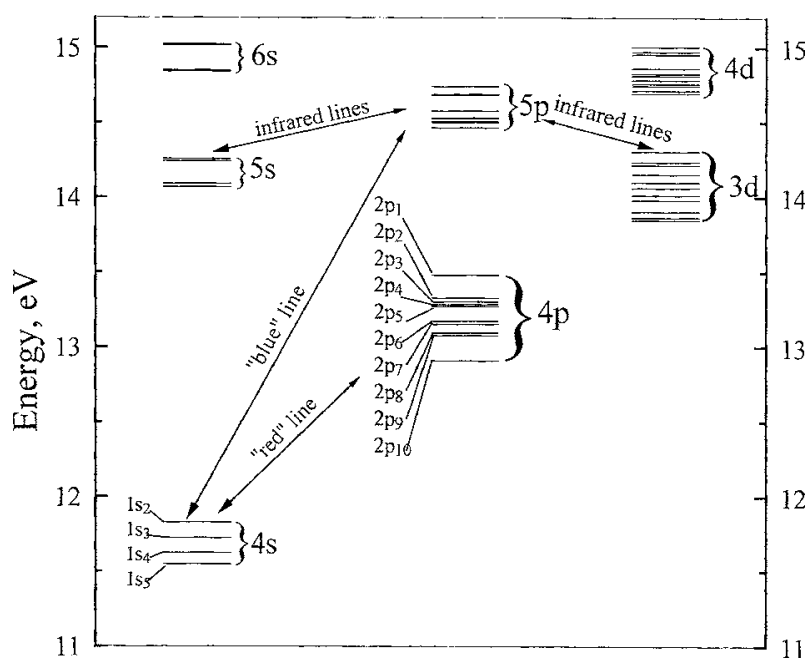

FIG. 2. Energy level diagram of argon electronic excited states.

$$
S_{0}=\frac{R_{0}}{R_{0}+\sum_{i=1}^{n} R_{q, i}}=\frac{k_{0}}{k_{0}+\sum_{i=1}^{n} k_{q, i} C_{i}} 100 \%,
$$

where $C_{i}$ is the concentration of species $i$.

From our previous experimental observations, ${ }^{11}$ fluorescence is easily detected if $S_{0}$ is larger than $0.02 \%$ and if there are sufficient quantities of the excited species. The minimum detectable concentration of a species by fluorescence may be estimated from the detection limit of the instrument, which can be calculated using the SBR-RSDB approach, ${ }^{34}$

$$
\mathrm{DL}=0.03 \mathrm{RSDB} \frac{C_{0}}{\mathrm{SBR}},
$$

where DL is the detection limit of the instrument, RSDB is the relative standard deviation of the background signal, $C_{0}$ is the analyte concentration, and SBR is the signal to background ratio. Previous experiments ${ }^{35}$ in the same reactor under similar reaction conditions showed that the $\mathrm{NO}(A)$ intensity is 7200 counts in 150 ppm NO in $\mathrm{N}_{2}$, while the intensity of the background and the relative standard deviation are 120 and 20 counts, respectively. Thus, SBR is 60 and RSDB is 20 for this condition. The corresponding concentration of $\mathrm{NO}(A)$ calculated from a reliable reaction model ${ }^{14}$ is 3.5 $\times 10^{-6} \mathrm{ppm}\left(1.42 \times 10^{-16} \mathrm{~mol} \mathrm{~cm}^{-3}\right)$. Substituting these values into Eq. (9), results in an estimated fluorescence detection limit of about $3.5 \times 10^{-8} \mathrm{ppm}$. Therefore, if optical emission of an excited species is not detected and $S_{0}$ for that species is larger than $0.02 \%$, the concentration of that species is expected to be less than $\sim 3.5 \times 10^{-8} \mathrm{ppm} \quad(1.42$ $\left.\times 10^{-18} \mathrm{~mol} \mathrm{~cm}^{-3}\right)$.

\section{B. Optical emission of UHP argon}

Argon is an inert atomic gas with the ground state electron configuration $1 s^{2} 2 s^{2} 2 p^{6} 3 s^{2} 3 p^{6}$. When highly energetic electrons collide with argon, one electron in the $3 p$ orbital can be excited to a higher energy level orbital. Figure 2 shows an energy level diagram with seven groups of excited states of argon, ${ }^{36}$ which correspond to one $3 p$ electron ex- cited into $4 s, 4 p, 3 d, 5 s, 5 p, 4 d$, and $6 s$ orbitals, as labeled in the figure. Selectivity rules based on electron spin and resonance dictate allowed transitions and energy levels. For example, a $3 p$ electron may be excited to any of 4 excited states within each $4 s, 5 s$, and $6 s$ orbital, 10 excited states within each $4 p$ and $5 p$ orbital, and 12 excited states in each $3 d$ and $4 d$ orbital. ${ }^{36,37}$ The excited states in Fig. 2 are labeled with the Paschen notation, ${ }^{38}$ which corresponds to the more common term symbol notation (e.g., the four $3 p^{5} 4 s$ states, in order of increasing energy, are $1 s_{5}, 1 s_{4}, 1 s_{3}$, and $1 s_{2}$ in the Paschen notation, which are equivalent to the term symbols ${ }^{3} P_{2},{ }^{3} P_{1},{ }^{3} P_{0}$, and $\left.{ }^{1} P_{1}\right)$.

Figure 3(a) shows the optical emission of UHP argon measured between 220 and $1000 \mathrm{~nm}$ at a pulse frequency of $200 \mathrm{~Hz}$. Similar optical emission spectra are observed at other pulse frequencies. No significant fluorescence is observed from 220 to $680 \mathrm{~nm}$ and from 880 to $1000 \mathrm{~nm}$. Strong fluorescence is observed in the wavelength range from 680 to $880 \mathrm{~nm}$, as shown in Fig. 3(b). The excited sates of $\mathrm{Ar}$ in the PCDR were deduced by comparison of the observed optical emission spectra with the standard optical spectra of argon. ${ }^{37}$

\section{Optical emission from the $5 p$ level}

The excited states of Ar with an electron in the $5 p$ level radiatively decay by three pathways, ${ }^{36,37,39}$

$$
\begin{aligned}
\operatorname{Ar}(5 p) & \rightarrow \operatorname{Ar}(4 s)+h \nu(394-471 \mathrm{~nm}) \\
& \rightarrow \operatorname{Ar}(5 s)+h \nu(1.9-6.0 \mu \mathrm{m}) \\
& \rightarrow \operatorname{Ar}(3 d)+h \nu(1.4-8.0 \mu \mathrm{m}) .
\end{aligned}
$$

The transitions from $5 p$ to $3 d$ and $5 s$ mainly produce infrared radiation, as shown in Fig. 2, which falls outside the detection range of our apparatus. The transitions from $5 p$ to $4 s$ produce blue light, as shown in Fig. 2, which is within our detection range. Investigations by Inoue et al. ${ }^{36}$ showed that about $20 \%$ of the $\operatorname{Ar}(5 p)$ radiative decay process is associated with the $\operatorname{Ar}(5 p \rightarrow 4 s)$ blue transition. Table II shows the radiation emission data for the $\operatorname{Ar}(5 p \rightarrow 4 s)$ transition and quenching rate constants of excited states of $\operatorname{Ar}(5 p)$ levels. Argon is the only quench atom in these experiments. The mole concentration of argon is $5.64 \times 10^{-5} \mathrm{~mol} \mathrm{~cm}^{-3}$ at $141 \mathrm{kPa}$ and $300 \mathrm{~K}$. Using this argon concentration and published rate constants ${ }^{36}$ for radiative emission and quenching by argon, the selectivities of natural radiation from the $\operatorname{Ar}(5 p)$ level are calculated from Eq. (8). As shown in Table II, $S_{0}$ for all $\operatorname{Ar}(5 p \rightarrow 4 s)$ transitions are larger than $0.02 \%$. Therefore, if electron collision reactions with argon produce appreciable $\operatorname{Ar}(5 p)$ excited states $\left(>\sim 3.5 \times 10^{-8} \mathrm{ppm}\right)$, all blue lines corresponding to the $\operatorname{Ar}(5 p \rightarrow 4 s)$ transition from 394-471 nm should be observed. However, no blue lines in this wavelength range are observed, as shown in Fig. 3, which indicates that the $\operatorname{Ar}(5 p)$ excited states are negligible in our nonthermal plasma reactor.

\section{Optical emission from $3 d$ and 5 s levels}

Nearly all argon $3 d$ and $5 s$ excited states relax into $\operatorname{Ar}(4 p)$ excited states. ${ }^{37}$ Due to the close energy level spacing 




(a) $220-1000 \mathrm{~nm}$ region

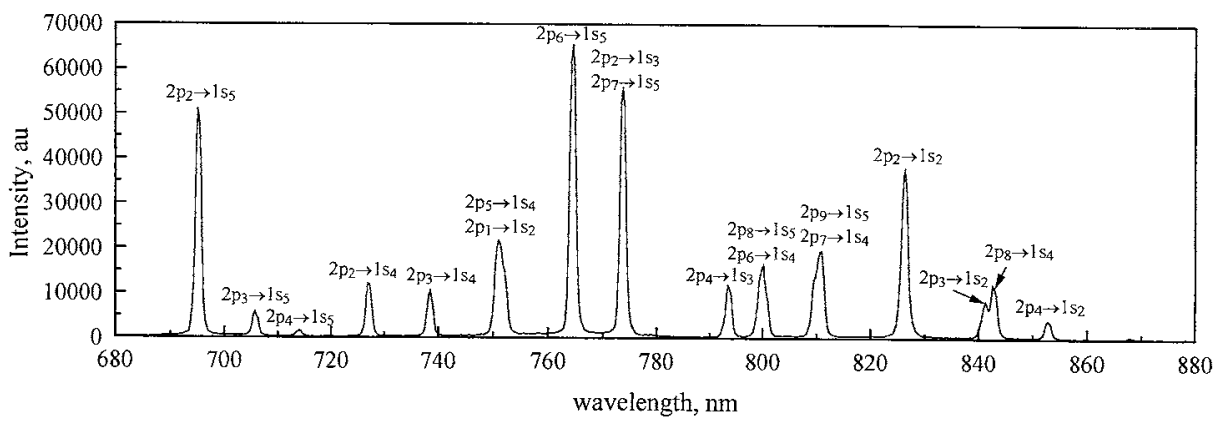

(b) $680-880 \mathrm{~nm}$ region
FIG. 3. Optical emission spectra of UHP Ar at the pulse frequency of $200 \mathrm{~Hz}$. between $\operatorname{Ar}(3 d, 5 s)$ and $\operatorname{Ar}(4 p)$, the wavelengths of most of the numerous emission lines between these levels are larger than $1000 \mathrm{~nm}$ (Ref. 37) and fall outside the detection range of our apparatus. However, four lines with wavelengths of 887.5 and $934.1 \mathrm{~nm}[\operatorname{Ar}(3 d \rightarrow 4 p)$ transitions $]$ and 919.5 and $929.2 \mathrm{~nm}[\operatorname{Ar}(5 s \rightarrow 4 p)$ transitions] could be detected, if present. The natural radiation lifetimes of each $\operatorname{Ar}(3 d)$ and $\operatorname{Ar}(5 s)$ states are about $50 \mathrm{~ns} .^{36,40}$ There are no reports on the quenching rate constants of the $\operatorname{Ar}(3 d)$ and $\operatorname{Ar}(5 s)$ states by argon. However, the energy level of the $\operatorname{Ar}(3 d)$ and $\operatorname{Ar}(5 s)$ states are between the $\operatorname{Ar}(5 p)$ and $\operatorname{Ar}(4 p)$, as shown in Fig. 2. The quenching rate constants of the $\operatorname{Ar}(3 d)$ and $\operatorname{Ar}(5 s)$ states by argon should be on order of the quenching rate constants of the $\operatorname{Ar}(5 p)$ and $\operatorname{Ar}(4 p)$ levels, which are $\sim 10^{13}-10^{14} \mathrm{~cm}^{3} \mathrm{~mol}^{-1} \mathrm{~s}^{-1}$, as shown in Tables II and III. ${ }^{36,38,41}$ For the upper limit of $10^{14} \mathrm{~cm}^{3} \mathrm{~mol}^{-1} \mathrm{~s}^{-1}$ as the quenching rate constant for $\operatorname{Ar}(3 d)$ and $\operatorname{Ar}(5 s)$ states, which is approximately the kinetic limit of the quenching reaction at room temperature, $S_{0}$ from Eq. (8) for the $\operatorname{Ar}(3 d)$ and $\operatorname{Ar}(5 s)$ states is about $0.35 \%$, which is much larger than the limit of $0.02 \%$. Therefore, if electron collision reactions with argon produce appreciable $\operatorname{Ar}(3 d)$ and $\operatorname{Ar}(5 s)$ excited states, these four lines should be detected between 880 and $940 \mathrm{~nm}$. Again, these lines are not observed, as shown in Fig. 3. Therefore, no appreciable quantities of $\operatorname{Ar}(3 d)$ or $\operatorname{Ar}(5 s)$ excited states appear to be formed.

\section{Optical emission from $4 p$ levels}

Deactivation of $\operatorname{Ar}(4 p)$ to the ground state is improbable and does not appreciably occur. ${ }^{38}$ Therefore, the $\operatorname{Ar}(4 p)$ states can only relax into $\operatorname{Ar}(4 s)$ states by radiative emission, which mainly produce light at red wavelengths, as shown in Fig. 2. Using the known argon concentration and published rate constants ${ }^{38,41}$ of radiative emission and quenching of $\operatorname{Ar}(4 p)$ by argon as shown in Table III, $S_{0}$ can be calculated from Eq. (8). $S_{0}$ for all the $\operatorname{Ar}(4 p \rightarrow 4 s)$ transition are $1.3 \%-$ $5.2 \%$ (Table III), which is roughly two orders of magnitude larger than $0.02 \%$. As shown in Fig. 3(b) and Table III, the principle optical emission peaks of all the $\operatorname{Ar}(4 p)$ excited states except $\operatorname{Ar}\left(2 p_{10}\right)$ are detected, which indicates that the $\operatorname{Ar}(4 p)$ excited states are formed in our nonthermal plasma reactor in appreciable amounts.

The principal products of $\operatorname{Ar}(4 p)$ quenched by argon are $\operatorname{Ar}(4 s)$ level excited states. ${ }^{38,42}$ Tachibana $^{43}$ showed that $25-40 \%$ of the total excitation of the $\operatorname{Ar}(4 p)$ levels cascades to each of the $1 s_{5}, 1 s_{4}$, and $1 s_{2}$ levels, while the contribution to the $1 s_{3}$ level only amounts to about $7 \%$ because the number of allowed transitions to this level is small.

\section{Optical emission from $4 \mathrm{~s}$ levels}

The four excited states of the $\operatorname{Ar}(4 s)$ level can be quenched by argon through both two-body and three-body quenching reactions. ${ }^{44,45}$ Table IV shows radiative emission data for the $\operatorname{Ar}(4 s \rightarrow$ ground state) transition and quenching rate constants of $\operatorname{Ar}(4 s)$ levels. Two excited states, $\operatorname{Ar}\left(1 s_{4}\right)$ and $\operatorname{Ar}\left(1 s_{2}\right)$, have a natural radiation lifetime of less than $10 \mathrm{~ns}$. For these states, $S_{0}$ calculated from Eq. (8) are higher than $90 \%$. However, both of them emit light at $\sim 100 \mathrm{~nm}$, beyond the minimum detection limit of $220 \mathrm{~nm}$ for our detector. The other two excited states, $\operatorname{Ar}\left(1 s_{5}\right)$ and $\operatorname{Ar}\left(1 s_{3}\right)$, are predominantly quenched by argon because of long natural radiation lifetimes $(38-45 \mathrm{~s}) .^{46-49}$ Although the $\operatorname{Ar}(4 s)$ levels are undetectable with our apparatus, we suspect excited $\operatorname{Ar}(4 s)$ atoms are produced in large quantities from direct electron collision reactions with argon because the excitation rate coefficient of the $\operatorname{Ar}(4 s)$ levels are about twice as large as the $\operatorname{Ar}(4 p)$ levels when the electric field to gas density $(E / N)$ ratio is $5 \times 10^{-17}-5 \times 10^{-15} \mathrm{~V} \mathrm{~cm}^{2},{ }^{43}$ which is a typical operation range of nonthermal plasma reactors. ${ }^{50}$ Therefore, in addition to the $\operatorname{Ar}(4 s)$ formed from the $\operatorname{Ar}(4 p)$ decay, 
TABLE II. Radiative emission data for $\operatorname{Ar}(5 p \rightarrow 4 s)$ transitions and quenching of $\operatorname{Ar}(5 p)$ levels.

\begin{tabular}{|c|c|c|c|c|c|c|c|}
\hline $\begin{array}{l}\text { Upper } \\
\text { level }\end{array}$ & $\begin{array}{l}\text { Lower } \\
\text { level }\end{array}$ & $\begin{array}{c}\text { Transition } \\
\text { branch ratio }(\%)^{\mathrm{a}}\end{array}$ & $\begin{array}{l}\text { Wavelength } \\
(\mathrm{nm})^{\mathrm{b}}\end{array}$ & $\begin{array}{c}\text { Natural } \\
\text { lifetime }(\mathrm{ns})^{\mathrm{a}}\end{array}$ & $\begin{array}{c}k_{q} \text { by } \mathrm{Ar} \\
\left(\mathrm{cm}^{3} \mathrm{~mol}^{-1} \mathrm{~s}^{-1}\right)^{\mathrm{a}}\end{array}$ & $\begin{array}{l}\mathrm{S}_{0} \\
(\%)\end{array}$ & Obs. ${ }^{c}$ \\
\hline $3 p_{1}$ & $1 s_{2}$ & 100 & 425.9 & 251 & $\cdots$ & $\cdots$ & $\mathrm{N}$ \\
\hline \multirow[t]{4}{*}{$3 p_{2}$} & $1 s_{2}$ & 23 & 433.4 & 100 & $1.63 \times 10^{14}$ & 0.109 & $\mathrm{~N}$ \\
\hline & $1 s_{3}$ & 34 & 418.2 & & & & $\mathrm{~N}$ \\
\hline & $1 s_{4}$ & 4 & 404.4 & & & & $\mathrm{~N}$ \\
\hline & $1 s_{5}$ & 39 & 394.8 & & & & $\mathrm{~N}$ \\
\hline \multirow[t]{3}{*}{$3 p_{3}$} & $1 s_{2}$ & 52 & 433.5 & 123 & $2.53 \times 10^{14}$ & 0.057 & $\mathrm{~N}$ \\
\hline & $1 s_{4}$ & 39 & 404.6 & & & & $\mathrm{~N}$ \\
\hline & $1 s_{5}$ & 9 & 394.9 & & & & $\mathrm{~N}$ \\
\hline \multirow[t]{3}{*}{$3 p_{4}$} & $1 s_{2}$ & 34 & 434.5 & 145 & $3.37 \times 10^{14}$ & 0.036 & $\mathrm{~N}$ \\
\hline & $1 s_{3}$ & 64 & 419.1 & & & & $\mathrm{~N}$ \\
\hline & $1 s_{4}$ & 2 & 405.5 & & & & $\mathrm{~N}$ \\
\hline \multirow[t]{2}{*}{$3 p_{5}$} & $1 s_{2}$ & 26 & 451.1 & 100 & $1.63 \times 10^{14}$ & 0.109 & $\mathrm{~N}$ \\
\hline & $1 s_{4}$ & 74 & 419.8 & & & & $\mathrm{~N}$ \\
\hline \multirow[t]{2}{*}{$3 p_{6}$} & $1 s_{4}$ & 18 & 426.6 & 106 & $2.05 \times 10^{14}$ & 0.082 & $\mathrm{~N}$ \\
\hline & $1 s_{5}$ & 82 & 415.9 & & & & $\mathrm{~N}$ \\
\hline \multirow[t]{3}{*}{$3 p_{7}$} & $1 s_{2}$ & 8 & 459.6 & 128 & $2.23 \times 10^{14}$ & 0.062 & $\mathrm{~N}$ \\
\hline & $1 s_{4}$ & 71 & 427.2 & & & & $\mathrm{~N}$ \\
\hline & $1 s_{5}$ & 21 & 416.4 & & & & $\mathrm{~N}$ \\
\hline \multirow[t]{3}{*}{$3 p_{8}$} & $1 s_{2}$ & 6 & 462.8 & 118 & $2.29 \times 10^{14}$ & 0.066 & $\mathrm{~N}$ \\
\hline & $1 s_{4}$ & 64 & 430.0 & & & & $\mathrm{~N}$ \\
\hline & $1 s_{5}$ & 30 & 419.1 & & & & $\mathrm{~N}$ \\
\hline $3 p_{9}$ & $1 s_{5}$ & 100 & 420.1 & 132 & $7.22 \times 10^{13}$ & 0.186 & $\mathrm{~N}$ \\
\hline \multirow[t]{4}{*}{$3 p_{10}$} & $1 s_{2}$ & 34 & 470.2 & 141 & $3.01 \times 10^{14}$ & 0.042 & $\mathrm{~N}$ \\
\hline & $1 s_{3}$ & 26 & 452.2 & & & & $\mathrm{~N}$ \\
\hline & $1 s_{4}$ & 4 & 436.4 & & & & $\mathrm{~N}$ \\
\hline & $1 s_{5}$ & 36 & 425.1 & & & & $\mathrm{~N}$ \\
\hline
\end{tabular}

${ }^{\mathrm{a}}$ Reference ${ }^{36}$

${ }^{\mathrm{c}}$ Line observability. $\mathrm{N}$ means line not observed.

$\operatorname{Ar}(4 s)$, as the lowest energy excited states of argon, are expected to be formed directly by electron collision reactions even more easily than the $\operatorname{Ar}(4 p)$ states that are clearly detected.

Therefore, we conclude that only the $\operatorname{Ar}(4 p)$ and $\operatorname{Ar}(4 s)$ levels are formed in nonthermal argon plasma. The higher energy excited states of argon are not formed in appreciable amounts. The $\operatorname{Ar}(4 p)$ and $\operatorname{Ar}(4 s)$ excited states can be produced from two sources:

(1) electron collision reaction [see (1)],

$$
e+\operatorname{Ar} \rightarrow \operatorname{Ar}(4 p, 4 s)+e,
$$

(2) ionization reactions and subsequent collision-radiative recombination reactions

$e+\mathrm{Ar} \rightarrow \mathrm{Ar}^{+}+2 e$,

$\mathrm{Ar}^{+}+\mathrm{Ar}+\mathrm{Ar} \rightarrow \mathrm{Ar}_{2}^{+}+\mathrm{Ar}$

$k=1.09 \times 10^{17} \mathrm{~cm}^{6} \mathrm{~mol}^{-2} \mathrm{~s}^{-1} \quad$ (Ref. 51)

$$
\begin{aligned}
& e+\operatorname{Ar}^{+} \rightarrow \operatorname{Ar}(4 p, 4 s), \\
& k=1.81 \times 10^{17} \mathrm{~cm}^{3} \mathrm{~mol}^{-1} \mathrm{~s}^{-1} \quad \text { (Ref. 52), } \\
& e+\mathrm{Ar}_{2}^{+} \rightarrow \operatorname{Ar}(4 p, 4 s)+\mathrm{Ar}, \\
& k=5.48 \times 10^{17} \mathrm{~cm}^{3} \mathrm{~mol}^{-1} \mathrm{~s}^{-1} \quad \text { (Ref. 53). }
\end{aligned}
$$

For example, Skrzypkowski et al. ${ }^{16}$ investigated the electron recombination reaction of $\mathrm{Ar}^{+}$and detected intense nearinfrared Ar lines between 700 and $850 \mathrm{~nm}$ originating from $\operatorname{Ar}(4 p \rightarrow 4 s)$ transitions. However, Bultel et $a l^{32}$ proposed that the products of the electron recombination reaction of $\mathrm{Ar}^{+}$are mainly $\operatorname{Ar}(4 s)$ states with negligible amounts of $\operatorname{Ar}(4 p)$. Shiu and Biondi ${ }^{54}$ and Kuo and Keto ${ }^{55}$ observed appreciable optical emission of $\operatorname{Ar}(4 p)$ from dissociative recombination reaction of $\mathrm{Ar}_{2}{ }^{+}$. Therefore, using only optical emission measurements with UHP argon, no conclusions can be drawn on whether the $\operatorname{Ar}(4 p)$ and $\operatorname{Ar}(4 s)$ levels shown in Fig. 3 are from direct electron collision reaction (10) or ionic recombination reactions (11)-(14). 
TABLE III. Radiative emission data for $\operatorname{Ar}(4 p \rightarrow 4 s)$ transitions and quenching of $\operatorname{Ar}(4 p)$ levels.

\begin{tabular}{|c|c|c|c|c|c|c|c|}
\hline $\begin{array}{l}\text { Upper } \\
\text { level }\end{array}$ & $\begin{array}{c}\text { Lower } \\
\text { level }\end{array}$ & $\begin{array}{c}\text { Transition } \\
\text { branch ratio }(\%)^{\mathrm{a}}\end{array}$ & $\begin{array}{l}\text { Wavelength } \\
\qquad(\mathrm{nm})^{\mathrm{b}}\end{array}$ & $\begin{array}{c}\text { Natural } \\
\text { lifetime (ns) }\end{array}$ & $\begin{array}{c}k_{q} \text { by Ar } \\
\left(\mathrm{cm}^{3} \mathrm{~mol}^{-1} \mathrm{~s}^{-1}\right)^{\mathrm{d}}\end{array}$ & $\begin{array}{c}S_{o} \\
(\%)\end{array}$ & Obs. ${ }^{e}$ \\
\hline \multirow[t]{2}{*}{$2 p_{1}$} & $1 s_{2}$ & 100 & 750.4 & 21.7 & $2.41 \times 10^{13}$ & 3.51 & $\mathrm{Y}$ \\
\hline & $1 s_{4}$ & $\sim 0$ & 667.7 & & & & $\mathrm{~N}$ \\
\hline \multirow[t]{4}{*}{$2 p_{2}$} & $1 s_{2}$ & 42.6 & 826.5 & 28.3 & $1.14 \times 10^{13}$ & 2.91 & $\mathrm{Y}$ \\
\hline & $1 s_{3}$ & 33.1 & 772.4 & & & & $\mathrm{Y}$ \\
\hline & $1 s_{4}$ & 5.1 & 727.3 & & & & $\mathrm{Y}$ \\
\hline & $1 s_{5}$ & 19.2 & 696.5 & & & & $\mathrm{Y}$ \\
\hline \multirow[t]{3}{*}{$2 p_{3}$} & $1 s_{2}$ & 63.0 & 840.8 & 29.0 & $1.87 \times 10^{13}$ & 2.92 & $\mathrm{Y}$ \\
\hline & $1 s_{4}$ & 24.3 & 738.4 & & & & $\mathrm{Y}$ \\
\hline & $1 s_{5}$ & 12.7 & 706.7 & & & & $\mathrm{Y}$ \\
\hline \multirow[t]{4}{*}{$2 p_{4}$} & $1 s_{2}$ & 43.1 & 852.1 & 29.3 & $2.11 \times 10^{13}$ & 1.25 & $\mathrm{Y}$ \\
\hline & $1 s_{3}$ & 54.8 & 794.8 & & & & $\mathrm{Y}$ \\
\hline & $1 s_{4}$ & 0.07 & 747.2 & & & & $\mathrm{~N}$ \\
\hline & $1 s_{5}$ & 2.1 & 714.7 & & & & $\mathrm{Y}$ \\
\hline \multirow[t]{2}{*}{$2 p_{5}$} & $1 s_{2}$ & 0 & 857.8 & 24.4 & $2.83 \times 10^{13}$ & 2.71 & $\mathrm{~N}$ \\
\hline & $1 s_{4}$ & 100 & 751.5 & & & & $\mathrm{Y}$ \\
\hline \multirow[t]{3}{*}{$2 p_{6}$} & $1 s_{2}$ & 13.3 & 922.5 & 29.4 & $2.17 \times 10^{13}$ & 2.50 & $\mathrm{~N}$ \\
\hline & $1 s_{4}$ & 11.3 & 800.6 & & & & $\mathrm{Y}$ \\
\hline & $1 s_{5}$ & 75.4 & 763.5 & & & & $\mathrm{Y}$ \\
\hline \multirow[t]{4}{*}{$2 p_{7}$} & $1 s_{2}$ & 3.0 & 935.4 & 30.2 & $4.64 \times 10^{13}$ & 2.79 & $\mathrm{~N}$ \\
\hline & $1 s_{3}$ & 7.8 & 866.8 & & & & $\mathrm{~N}$ \\
\hline & $1 s_{4}$ & 74.4 & 810.4 & & & & $\mathrm{Y}$ \\
\hline & $1 s_{5}$ & 14.8 & 772.4 & & & & $\mathrm{Y}$ \\
\hline \multirow[t]{3}{*}{$2 p_{8}$} & $1 s_{2}$ & 4.5 & 978.5 & 30.6 & $1.93 \times 10^{13}$ & 3.17 & $\mathrm{~N}$ \\
\hline & $1 s_{4}$ & 65.7 & 842.5 & & & & $\mathrm{Y}$ \\
\hline & $1 s_{5}$ & 29.8 & 801.5 & & & & $\mathrm{Y}$ \\
\hline $2 p_{9}$ & $1 s_{5}$ & 100 & 811.5 & 30.7 & $1.93 \times 10^{13}$ & 5.19 & $\mathrm{Y}$ \\
\hline \multirow[t]{4}{*}{$2 p_{10}$} & $1 s_{2}$ & 0.6 & 1148.8 & 40.5 & $1.20 \times 10^{13}$ & 3.28 & $\mathrm{~N}$ \\
\hline & $1 s_{3}$ & 3.6 & 1047.0 & & & & $\mathrm{~N}$ \\
\hline & $1 s_{4}$ & 21.8 & 965.8 & & & & $\mathrm{~N}$ \\
\hline & $1 s_{5}$ & 74.0 & 912.3 & & & & $\mathrm{~N}$ \\
\hline
\end{tabular}

${ }^{\mathrm{a}}$ Reference 38 .

${ }^{\mathrm{b}}$ Reference 37.

${ }^{\mathrm{c}}$ Reference 39.

${ }^{\mathrm{d}}$ References 38 and 41

${ }^{\mathrm{e}}$ Line observability. $\mathrm{N}$ means line not observed. Y means line observed.

TABLE IV. Radiative emission data for $\operatorname{Ar}(4 s \rightarrow \operatorname{Ar}$ ground state) transitions and quenching of $\operatorname{Ar}(4 s)$ levels.

\begin{tabular}{ccccc}
\hline \hline Ar $(4 s)$ level & $1 s_{5}\left({ }^{3} P_{2}\right)$ & $1 s_{4}\left({ }^{3} P_{1}\right)$ & $1 s_{3}\left({ }^{3} P_{0}\right)$ & $1 s_{2}\left({ }^{1} P_{1}\right)$ \\
\hline Natural radiation lifetime & $38 \mathrm{~s}$ & $9.5 \mathrm{~ns}$ & $44.9 \mathrm{~s}$ & $2.5 \mathrm{~ns}$ \\
Fluorescence wavelength $(\mathrm{nm})^{\mathrm{b}}$ & $\cdots$ & 106.67 & $\cdots$ & 104.82 \\
Two-body $k_{q}$ by Ar $\left(\mathrm{cm}^{3} \mathrm{~mol}^{-1} \mathrm{~s}^{-1}\right)^{\mathrm{c}}$ & $1.26 \times 10^{9}$ & $2.41 \times 10^{10}$ & $3.19 \times 10^{9}$ & $3.07 \times 10^{10}$ \\
Three-body $k_{q}$ by Ar $\left(\mathrm{cm}^{6} \mathrm{~mol}^{-2} \mathrm{~s}^{-1}\right)^{\mathrm{c}}$ & $2.17 \times 10^{15}$ & $2.54 \times 10^{15}$ & $3.01 \times 10^{15}$ & $9.42 \times 10^{14}$ \\
$S_{\mathrm{o}}(\%)$ & $\sim 0$ & 91.7 & $\sim 0$ & 98.8 \\
\hline
\end{tabular}

${ }^{\mathrm{a}}$ References 46-49.

${ }^{\mathrm{b}}$ Reference 83.

${ }^{\mathrm{c}}$ References 44 and 45. 




(a) $220-880 \mathrm{~nm}$

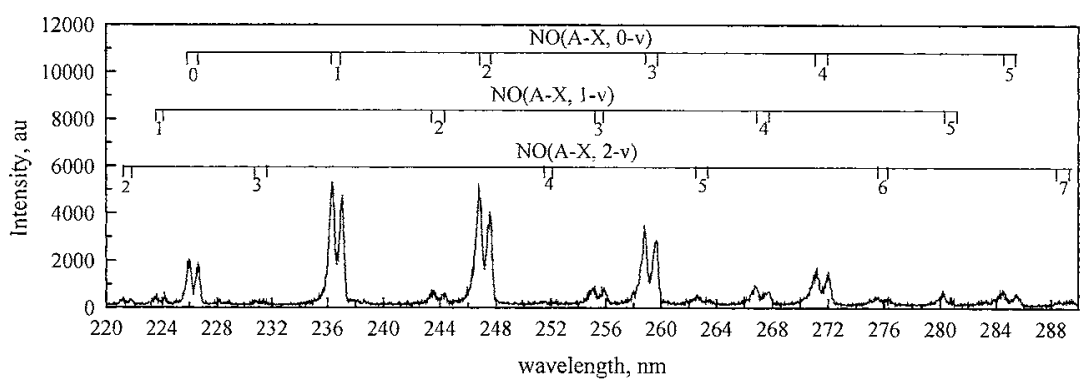

(b) $220-290 \mathrm{~nm}$

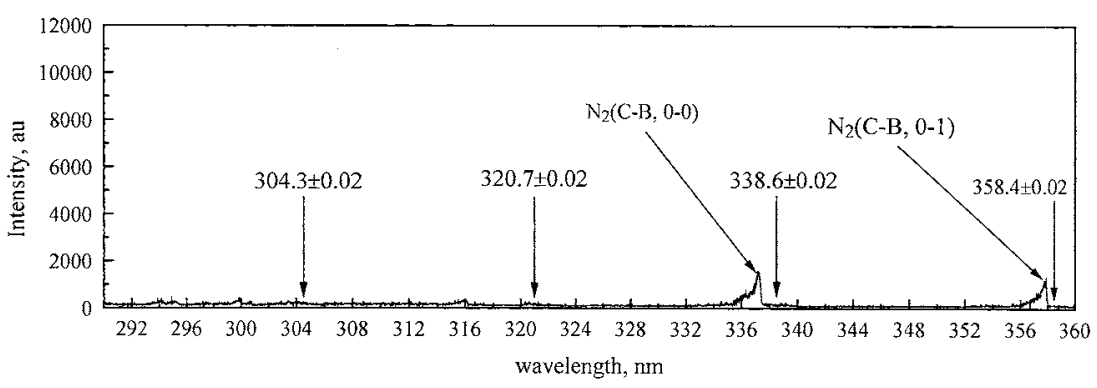

(c) $290-360 \mathrm{~nm}$

Recent investigations ${ }^{23,24}$ on the dissociative recombination of $\mathrm{NO}_{2}{ }^{+}$and $\mathrm{N}_{2} \mathrm{O}^{+}$with electrons showed that $\mathrm{NO}(\mathrm{B})$ is formed and detected in the optical emission spectra. Therefore, if $\mathrm{Ar}^{+}$or $\mathrm{Ar}_{2}^{+}$are the principal active species contributing to $\mathrm{NO}_{x}$ conversion through path $\mathrm{I}$ in nonthermal argon plasma, $\mathrm{NO}_{2}{ }^{+}$and $\mathrm{N}_{2} \mathrm{O}^{+}$should be produced from charge transfer reactions of $\mathrm{Ar}^{+}$or $\mathrm{Ar}_{2}^{+}$with $\mathrm{NO}_{2}$ or $\mathrm{N}_{2} \mathrm{O}$, with concomitant optical emission from the $\mathrm{NO}(\mathrm{B})$ produced from dissociative recombination reactions of $\mathrm{NO}_{2}^{+}$or $\mathrm{N}_{2} \mathrm{O}^{+}$. This hypothesis leads to the examination of $\mathrm{NO}_{2}$ and $\mathrm{N}_{2} \mathrm{O}$ decomposition in nonthermal argon plasma.

\section{Optical emission of $\mathrm{N}_{2} \mathrm{O}$ in $\mathrm{Ar}$}

Figure 4(a) shows the optical emission spectra from $290 \mathrm{ppm} \mathrm{N}_{2} \mathrm{O}$ in $\mathrm{Ar}$ at a pulse frequency of $200 \mathrm{~Hz}$ with a power input of $31.0 \mathrm{~W}$. The observed optical emissions arise from excited states of three species: $\mathrm{NO}[\mathrm{NO}(A)], \mathrm{N}_{2}\left[\mathrm{~N}_{2}(C)\right.$ and $\left.\mathrm{N}_{2}(B)\right]$, and argon $[\operatorname{Ar}(4 p)]$. The excited states of $\operatorname{Ar}(4 p)$ are also detected, as expected when argon is the balance gas (Fig. 3).

For $\mathrm{N}_{2} \mathrm{O}$ conversion in Ar plasma, the principal species in the reactor are $\mathrm{N}_{2}, \mathrm{O}_{2}$, unconverted $\mathrm{N}_{2} \mathrm{O}$, and Ar. Other by-products should be less than $5 \mathrm{ppm}$, as determined from FTIR measurements. The concentration of $\mathrm{N}_{2} \mathrm{O}$ at the reactor outlet quantified by FTIR is $60 \mathrm{ppm}$. From a previously published lumped kinetic model ${ }^{12}$ and reaction mechanism, ${ }^{33}$ the calculated $\mathrm{N}_{2} \mathrm{O}$ concentration in the reactor at the window used for optical emission detection is $125 \mathrm{ppm}$. From mass balance, the concentrations of $\mathrm{N}_{2}$ and $\mathrm{O}_{2}$ at the window are 165 and $82.5 \mathrm{ppm}$. Therefore, the mole concentrations of Ar, $\mathrm{N}_{2} \mathrm{O}, \mathrm{N}_{2}$, and $\mathrm{O}_{2}$ at the window at $300 \mathrm{~K}$ and $141 \mathrm{kPa}$ are $5.64 \times 10^{-5}, 7.05 \times 10^{-9}, 9.31 \times 10^{-9}, 4.65 \times 10^{-9} \mathrm{~mol} \mathrm{~cm}^{-3}$, respectively. If, as many investigators have reported, ${ }^{1,7,9,10,35}$ positive ions are the major active species contributing to plasma reactions, the following reactions should occur

$$
\begin{aligned}
& \mathrm{Ar}^{+}+\mathrm{Ar}+\mathrm{Ar} \rightarrow \mathrm{Ar}_{2}^{+}+\mathrm{Ar}, \\
& k=1.09 \times 10^{17} \mathrm{~cm}^{6} \mathrm{~mol}^{-2} \mathrm{~s}^{-1} \quad \text { (Ref. 51), } \\
& \mathrm{Ar}^{+}+\mathrm{N}_{2} \mathrm{O} \rightarrow \mathrm{N}_{2} \mathrm{O}^{+}+\mathrm{Ar},
\end{aligned}
$$$$
k=1.75 \times 10^{14} \mathrm{~cm}^{3} \mathrm{~mol}^{-1} \mathrm{~s}^{-1} \quad \text { (Ref. 56), }
$$ 


$$
\begin{aligned}
& \mathrm{Ar}^{+}+\mathrm{N}_{2} \rightarrow \mathrm{N}_{2}^{+}+\mathrm{Ar}, \\
& k=6.62 \times 10^{12} \mathrm{~cm}^{3} \mathrm{~mol}^{-1} \mathrm{~s}^{-1} \quad(\text { Ref. 56), } \\
& \mathrm{Ar}^{+}+\mathrm{O}_{2} \rightarrow \mathrm{O}_{2}^{+}+\mathrm{Ar}, \\
& k=2.77 \times 10^{13} \mathrm{~cm}^{3} \mathrm{~mol}^{-1} \mathrm{~s}^{-1} \quad(\text { Ref. 56) }
\end{aligned}
$$

Using these reactant concentrations and the rate constants for parallel reactions (12) and (15)-(17), the Ar selectivities of (12) and (15)-(17) are estimated to be $99.6 \%, 0.4 \%, 0 \%$, and $0 \%$, respectively, which implies that $\mathrm{Ar}^{+}$is predominantly converted into $\mathrm{Ar}_{2}{ }^{+}$without significant reactions with $\mathrm{N}_{2} \mathrm{O}$, $\mathrm{N}_{2}$, or $\mathrm{O}_{2}$. However, $\mathrm{Ar}_{2}{ }^{+}$can further react with $\mathrm{N}_{2} \mathrm{O}, \mathrm{N}_{2}$, and $\mathrm{O}_{2}$ in the following charge transfer reactions:

$$
\begin{aligned}
& \mathrm{Ar}_{2}^{+}+\mathrm{N}_{2} \mathrm{O} \rightarrow \mathrm{N}_{2} \mathrm{O}^{+}+2 \mathrm{Ar}, \\
& k=4.94 \times 10^{14} \mathrm{~cm}^{3} \mathrm{~mol}^{-1} \mathrm{~s}^{-1} \quad \text { (Ref. 57), } \\
& \mathrm{Ar}_{2}^{+}+\mathrm{N}_{2} \rightarrow \mathrm{N}_{2}^{+}+2 \mathrm{Ar}, \\
& k=1.32 \times 10^{14} \mathrm{~cm}^{3} \mathrm{~mol}^{-1} \mathrm{~s}^{-1} \quad \text { (Ref. 58), } \\
& \mathrm{Ar}_{2}^{+}+\mathrm{O}_{2} \rightarrow \mathrm{O}_{2}^{+}+2 \mathrm{Ar}^{+} \\
& k=4.45 \times 10^{13} \mathrm{~cm}^{3} \mathrm{~mol}^{-1} \mathrm{~s}^{-1} \quad \text { (Ref. 56). }
\end{aligned}
$$

The calculated selectivities of (18)-(20) are 70.8\%, 25.0\%, and $4.2 \%$, respectively. Therefore, most $(70.8 \%)$ of $\mathrm{Ar}_{2}{ }^{+}$(derived from $\mathrm{Ar}^{+}$) should contribute to the $\mathrm{N}_{2} \mathrm{O}^{+}$formation through reaction (18). Johnsen et al. ${ }^{23,24}$ found that the dissociative recombination reactions of $\mathrm{N}_{2} \mathrm{O}^{+}$produce the strongest fluorescence from $\mathrm{NO}(B)$, the weaker fluorescence from $\mathrm{NO}(A)$, and the weakest fluorescence from $\mathrm{N}_{2}(C)$. Therefore, if $\mathrm{Ar}_{2}{ }^{+}$(derived from $\mathrm{Ar}^{+}$) is responsible for $\mathrm{N}_{2} \mathrm{O}$ conversion, $\mathrm{N}_{2} \mathrm{O}^{+}$should be generated and optical emission from $\mathrm{NO}(B), \mathrm{NO}(A)$, and $\mathrm{N}_{2}(C)$ should be detected.

Figures 4(b) and 4(c) show the amplified optical emission detected at 220-290 and 290-360 nm, respectively. By comparing with the standard molecular spectra ${ }^{59}$ of $\mathrm{NO}(B)$, $\mathrm{NO}(A)$, and $\mathrm{N}_{2}(C)$, strong fluorescences from $\mathrm{NO}(A)$ and $\mathrm{N}_{2}(C)$ are observed. Three vibrational states of $\mathrm{NO}(A)$, with $v=0,1,2$, are observed. The optical emission intensity increases with decreasing vibrational state, which implies that $\mathrm{NO}(A)$ with $v=0$ is predominantly formed in the PCDR. The strongest optical emission lines for $\mathrm{NO}(B)$, if present, should therefore appear at wavelengths of 304.3, 320.7, 338.6, and $358.4 \mathrm{~nm}$, as reported by many investigators. ${ }^{27,59-61}$ However, Fig. 4(c) shows no optical emission at these wavelengths. One reason that $\mathrm{NO}(B)$ might not be observed is due to quenching by $\mathrm{Ar}, \mathrm{N}_{2} \mathrm{O}, \mathrm{N}_{2}$, and $\mathrm{O}_{2}$. However, this possibility can be discounted by the consideration of the following quenching and radiative emission reactions:

$$
\begin{aligned}
& \mathrm{NO}(B)+\mathrm{Ar} \rightarrow \text { products, } \\
& k=1.15 \times 10^{11} \mathrm{~cm}^{3} \mathrm{~mol}^{-1} \mathrm{~s}^{-1} \quad(\text { Ref. 62), }
\end{aligned}
$$

$$
\begin{aligned}
& \mathrm{NO}(B)+\mathrm{N}_{2} \mathrm{O} \rightarrow \text { products, } \\
& k=8.25 \times 10^{12} \mathrm{~cm}^{3} \mathrm{~mol}^{-1} \mathrm{~s}^{-1} \quad(\text { Ref. 63), } \\
& \mathrm{NO}(B)+\mathrm{N}_{2} \rightarrow \text { products, } \\
& k=2.89 \times 10^{11} \mathrm{~cm}^{3} \mathrm{~mol}^{-1} \mathrm{~s}^{-1} \quad \text { (Ref. 64), } \\
& \mathrm{NO}(B)+\mathrm{O}_{2} \rightarrow \text { products, } \\
& k=1.11 \times 10^{13} \mathrm{~cm}^{3} \mathrm{~mol}^{-1} \mathrm{~s}^{-1} \quad(\text { Ref. 64), } \\
& \mathrm{NO}(B) \rightarrow \mathrm{NO}^{2} h \nu, \\
& k=5.00 \times 10^{5} \mathrm{~s}^{-1} \quad(\text { Ref. } 27) .
\end{aligned}
$$

Using the previously calculated reactant concentrations with the rate constants in parallel reactions (21)-(25), $S_{\mathrm{o}}$ of $\mathrm{NO}(B)$ is estimated from Eq. (8) to be 7\%, which is sufficient for optical emission detection, if present. Similarly, $\mathrm{NO}(A)$ is deactivated by the following processes:

$$
\begin{aligned}
& \mathrm{NO}(A)+\mathrm{Ar} \rightarrow \text { products, } \\
& k=2.36 \times 10^{11} \mathrm{~cm}^{3} \mathrm{~mol}^{-1} \mathrm{~s}^{-1} \quad(\text { Ref. 65), } \\
& \mathrm{NO}(A)+\mathrm{N}_{2} \mathrm{O} \rightarrow \text { products, } \\
& k=2.84 \times 10^{14} \mathrm{~cm}^{3} \mathrm{~mol}^{-1} \mathrm{~s}^{-1} \quad \text { (Ref. 14), } \\
& \mathrm{NO}(A)+\mathrm{N}_{2} \rightarrow \text { products, } \\
& k=4.70 \times 10^{10} \mathrm{~cm}^{3} \mathrm{~mol}^{-1} \mathrm{~s}^{-1} \quad \text { (Ref. 14), } \\
& \mathrm{NO}(A)+\mathrm{O}_{2} \rightarrow \text { products, } \\
& k=9.09 \times 10^{13} \mathrm{~cm}^{3} \mathrm{~mol}^{-1} \mathrm{~s}^{-1} \quad \text { (Ref. 14), } \\
& \mathrm{NO}(A) \rightarrow \mathrm{NO}+h \nu, \\
& k=4.59 \times 10^{6} \mathrm{~s}^{-1} \quad \text { (Ref. 14). }
\end{aligned}
$$

The selectivity of the natural radiation of $\mathrm{NO}(A)$ is estimated from Eq. (8) to be $22 \%$, which is about three times $S_{\mathrm{o}}$ for $\mathrm{NO}(B)$. Therefore, if $\mathrm{N}_{2} \mathrm{O}^{+}$is formed from $\mathrm{Ar}_{2}{ }^{+}$(and indirectly from $\mathrm{Ar}^{+}$), which results in $\mathrm{NO}(A)$ formation and detection, $\mathrm{NO}(B)$ should also be formed and detected. Undetectable $\mathrm{NO}(B)$ suggests that $\mathrm{Ar}^{+}$and $\mathrm{Ar}_{2}{ }^{+}$do not contribute to $\mathrm{N}_{2} \mathrm{O}$ conversion. However, the observed optical emissions from $\mathrm{NO}(A)$ and $\mathrm{N}_{2}(C)$ must still be explained.

As discussed previously, the major excited states of argon formed in nonthermal Ar plasmas are $\operatorname{Ar}(4 p)$ and $\operatorname{Ar}(4 s)$. The reaction rate constant of $\operatorname{Ar}(4 p)$ with $\mathrm{N}_{2} \mathrm{O}$ has not been reported, but it is estimated in this work to be on order of $10^{14} \mathrm{~cm}^{3} \mathrm{~mol}^{-1} \mathrm{~s}^{-1}$. ${ }^{42}$ Due to the short radiation lifetimes (20-40 ns) and large quenching rate constants (on the order of $\left.10^{13} \mathrm{~cm}^{3} \mathrm{~mol}^{-1} \mathrm{~s}^{-1}\right)$ of $\operatorname{Ar}(4 p)$ excited states by $\mathrm{Ar}$ (Table III), the $\operatorname{Ar}(4 p)$ excited states are not expected to react appreciably with $\mathrm{N}_{2} \mathrm{O}, \mathrm{N}_{2}$, and $\mathrm{O}_{2}$ at the high prevailing concentration of argon. More than $95 \%$ of $\operatorname{Ar}(4 p)$ excited 


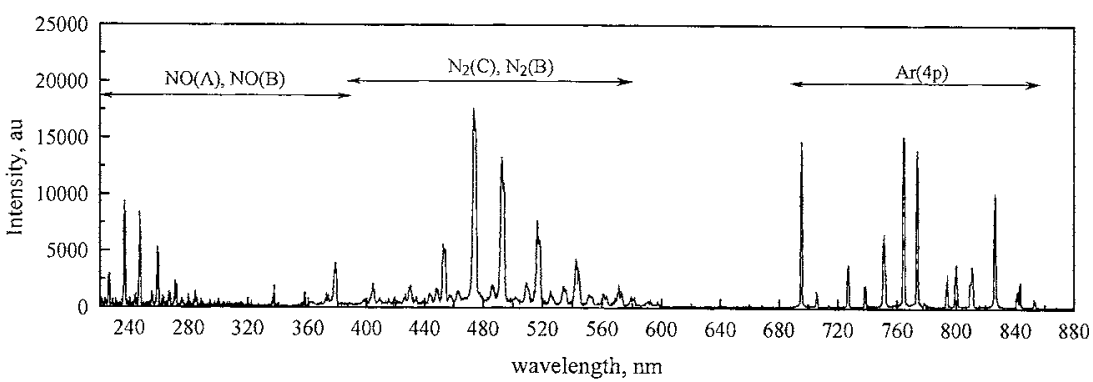

(a) $220-880 \mathrm{~nm}$

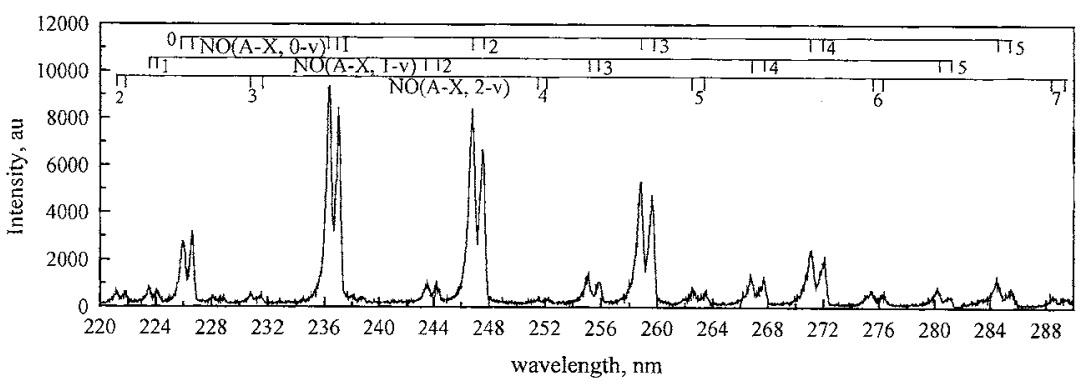

(b) $220-290 \mathrm{~nm}$

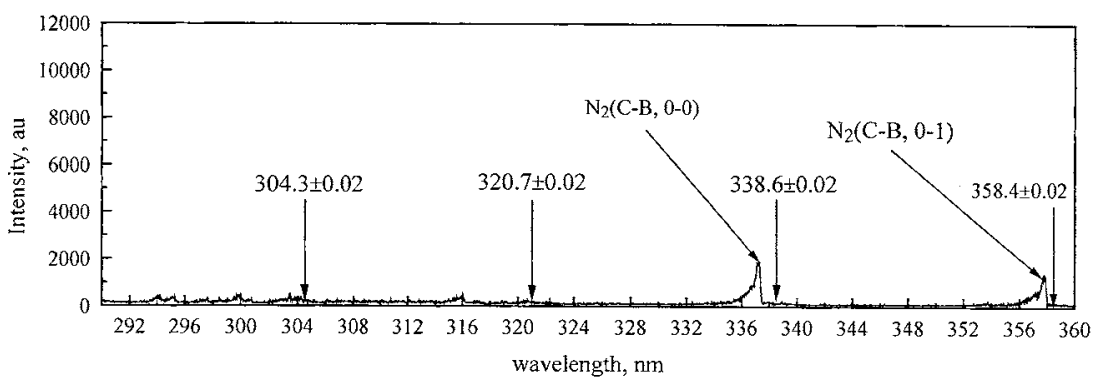

(c) $290-360 \mathrm{~nm}$

states are quenched to $\operatorname{Ar}(4 s)$ levels, as shown in Table III. Therefore, only $\operatorname{Ar}(4 s)$ excited states appear to contribute to $\mathrm{N}_{2} \mathrm{O}$ conversion in argon nonthermal plasma. Both $\operatorname{Ar}\left(1 s_{4}\right)$ and $\operatorname{Ar}\left(1 s_{2}\right)$ are not expected to contribute to any reactions with $\mathrm{N}_{2} \mathrm{O}, \mathrm{N}_{2}$, and $\mathrm{O}_{2}$ because of their very short radiation lifetimes $(<10 \mathrm{~ns}$, as shown in Table IV). Therefore, only the two long-life excited states of argon, $\operatorname{Ar}\left(1 s_{5}\right)$ and $\operatorname{Ar}\left(1 s_{3}\right)$, appear to contribute to reactions with $\mathrm{N}_{2} \mathrm{O}, \mathrm{N}_{2}$, and $\mathrm{O}_{2}$, with the result that the following well-established reactions contribute to the observed optical emission shown in Fig. 4:

$$
\begin{aligned}
& \operatorname{Ar}\left(1 s_{5}, 1 s_{3}\right)+\mathrm{N}_{2} \mathrm{O} \rightarrow \mathrm{Ar}+\mathrm{N}_{2}(B)+\mathrm{O}, \\
& k=2.65 \times 10^{14} \mathrm{~cm}^{3} \mathrm{~mol}^{-1} \mathrm{~s}^{-1} \quad(\text { Ref. 66), } \\
& \operatorname{Ar}\left(1 s_{5}, 1 s_{3}\right)+\mathrm{N}_{2} \rightarrow \mathrm{Ar}+\mathrm{N}_{2}(C), \\
& k=2.17 \times 10^{13} \mathrm{~cm}^{3} \mathrm{~mol}^{-1} \mathrm{~s}^{-1} \quad(\text { Ref. 67), } \\
& \mathrm{N}_{2}(C) \rightarrow \mathrm{N}_{2}(B)+h \nu, \\
& k=2.73 \times 10^{7} \mathrm{~cm}^{3} \mathrm{~mol}^{-1} \mathrm{~s}^{-1} \quad(\text { Ref. 68), }
\end{aligned}
$$

FIG. 5. Optical emission of $566 \mathrm{ppm}$ $\mathrm{NO}$ in $\mathrm{Ar}$ at the pulse frequency of $200 \mathrm{~Hz}$.

$$
\begin{aligned}
& \mathrm{N}_{2}(B) \rightarrow \mathrm{N}_{2}(A)+h \nu, \\
& k=2.00 \times 10^{5} \mathrm{~cm}^{3} \mathrm{~mol}^{-1} \mathrm{~s}^{-1} \quad(\text { Ref. 68), } \\
& \mathrm{N}_{2}(A)+\mathrm{O} \rightarrow \mathrm{NO}+\mathrm{N}, \\
& k=1.69 \times 10^{13} \mathrm{~cm}^{3} \mathrm{~mol}^{-1} \mathrm{~s}^{-1} \quad \text { (Ref. 69), } \\
& \mathrm{N}_{2}(A)+\mathrm{NO} \rightarrow \mathrm{NO}(A)+\mathrm{N}_{2}, \\
& k=3.85 \times 10^{13} \mathrm{~cm}^{3} \mathrm{~mol}^{-1} \quad(\text { Ref. 70), }
\end{aligned}
$$

\section{Optical emission of NO in Ar}

Similar experimental conditions and optical emission measurements were conducted for NO in Ar. Figure 5(a) shows the optical emission spectra from 566 ppm NO in Ar at a pulse frequency of $200 \mathrm{~Hz}$ with a power input of 31.0 W. The observed optical emissions belong to the same species identified in Fig. 4: $\mathrm{NO}[\mathrm{NO}(A)], \mathrm{N}_{2}\left[\mathrm{~N}_{2}(C)\right.$ and $\left.\mathrm{N}_{2}(B)\right]$, and argon $[\operatorname{Ar}(4 p)]$.

For NO conversion in Ar plasma, the species in the reactor are $\mathrm{N}_{2}, \mathrm{O}_{2}, \mathrm{NO}_{2}$, and unconverted $\mathrm{NO}$ and Ar. Other products are negligible, as determined from previous FTIR measurements. ${ }^{1}$ The concentrations of $\mathrm{NO}$ and $\mathrm{NO}_{2}$ at the 


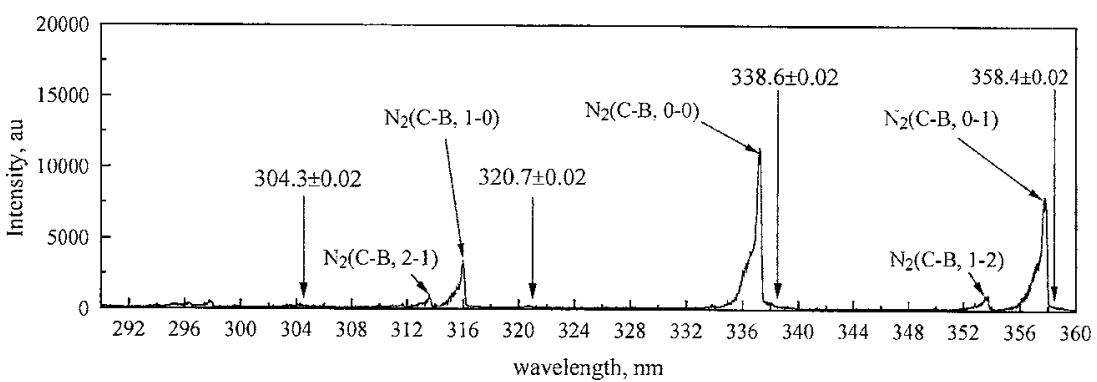

FIG. 6. Optical emission of $408 \mathrm{ppm}$ $\mathrm{N}_{2} \mathrm{O}$ in $\mathrm{N}_{2}$ at the pulse frequency of $200 \mathrm{~Hz}$.

reactor outlet measured by FTIR are 336 and 67 ppm, respectively. From a previously published lumped kinetic model and reaction mechanism, ${ }^{35}$ the calculated concentrations of $\mathrm{NO}$ and $\mathrm{NO}_{2}$ at the window used for optical emission detection are 425 and 53 ppm, respectively. From mass balance, the concentrations of $\mathrm{N}_{2}$ and $\mathrm{O}_{2}$ at the window are 44 and $17 \mathrm{ppm}$, respectively. Therefore, the concentrations of $\mathrm{Ar}, \mathrm{NO}, \mathrm{NO}_{2}, \mathrm{~N}_{2}$, and $\mathrm{O}_{2}$ at the window at $300 \mathrm{~K}$ and $141 \mathrm{kPa}$ are $5.64 \times 10^{-5}, 2.40 \times 10^{-8}, 2.99 \times 10^{-9}, 2.48$ $\times 10^{-9}$, and $9.59 \times 10^{-10} \mathrm{~mol} \mathrm{~cm}^{-3}$, respectively.

Through similar reasoning used for $\mathrm{N}_{2} \mathrm{O}$ conversion in $\mathrm{Ar}$, if $\mathrm{Ar}^{+}$or $\mathrm{Ar}_{2}{ }^{+}$is the major active species contributing to $\mathrm{NO}_{x}$ conversion, the optical emission of $\mathrm{NO}(B)$ formed during the dissociative recombination reaction of $\mathrm{NO}_{2}{ }^{+}$should again be observed. However, the results in Figs. 5(b) and 5(c) show that no optical emission from $\mathrm{NO}(B)$ is observed, which discounts the contribution of the $\mathrm{Ar}^{+}$or $\mathrm{Ar}_{2}^{+}$to $\mathrm{NO}_{x}$ conversion in nonthtermal argon plasma.

\section{E. Optical emission of $\mathrm{N}_{2} \mathrm{O}$ in $\mathrm{N}_{2}$}

Similar optical emission measurements were made for 408 ppm $\mathrm{N}_{2} \mathrm{O}$ in $\mathrm{N}_{2}$ at a pulse frequency of $200 \mathrm{~Hz}$ to explore the contribution of $\mathrm{N}_{2}{ }^{+}$in $\mathrm{N}_{2} \mathrm{O}$ conversion. Hu et al. ${ }^{10}$ proposed that $\mathrm{N}_{2}^{+}$was responsible for $\mathrm{N}_{2} \mathrm{O}$ conversion in nonthermal $\mathrm{N}_{2}$ plasma through the following reactions:

$$
\begin{aligned}
& e+\mathrm{N}_{2} \rightarrow \mathrm{N}_{2}^{+}+2 e, \\
& \mathrm{~N}_{2}^{+}+\mathrm{N}_{2} \mathrm{O} \rightarrow \mathrm{N}_{2} \mathrm{O}^{+}+\mathrm{N}_{2}, \quad k=3.01 \\
& \times 10^{14} \mathrm{~cm}^{3} \mathrm{~mol}^{-1} \mathrm{~s}^{-1}, \\
& e+\mathrm{N}_{2} \mathrm{O}^{+} \rightarrow \text { products. }
\end{aligned}
$$

If this mechanism is correct, optical emission of $\mathrm{NO}(B)$ from dissociative recombination of $\mathrm{N}_{2} \mathrm{O}^{+}$in (39) should be observed. However, the results in Fig. 6 again show no optical emissions from $\mathrm{NO}(B)$, which discounts the contribution of $\mathrm{N}_{2}{ }^{+}$to $\mathrm{N}_{2} \mathrm{O}$ conversion in nonthtermal nitrogen plasma. Those observations and results can be explained by examining the mechanism of streamer formation and propagation in corona discharges.

\section{F. Streamer mechanism of corona discharge}

Nonthermal plasma is a weakly ionized gas in which ions are present. ${ }^{71}$ The insignificance of charge transfer reactions in nonthermal plasma and the key role of radicals and excited molecules with long lifetimes in the observed reactions can be explained on the basis of nonthermal plasma discharges.

The accepted mechanism of nonthermal plasma discharge is the streamer theory, proposed by Leob and Meek in $1940 .^{72,73}$ A filamentlike streamer is a narrow-channel current that emits light and rapidly bridges and short-circuits overvolted discharge gaps in gases near atmospheric pressure. $^{74}$ From an electrostatic point of view, a streamer may be thought of as an elongated conductive needle from anode to cathode which transports potential from the anode into discharge gap.

Figure 7 illustrates the formation and development of a streamer. When the high voltage is applied to a wire-cylinder reactor, an external nonhomogeneous electric field between anode and cathode is established. The field strength can be calculated from ${ }^{75}$

$$
E_{e}(r)=\frac{U}{r \ln R_{1} / R_{2}},
$$

where $E_{e}$ is the external electric field, $r$ is the distance from the wire center to the point of concern, $U$ is the voltage applied between wire and tube, and $R_{1}$ and $R_{2}$ are the radius of the tube and the radius of the wire, respectively. From Eq. (40), the field near the wire is much stronger than that away from the wire. For our reactor, $U$ is about $20 \mathrm{kV} .^{1}$ The electric field at the surface of the wire is about $187 \mathrm{kV} \mathrm{cm}^{-1}$, which is high enough to ionize the gas. ${ }^{76}$ Once the gas molecules are ionized, the electrons expelled from the molecules are accelerated quickly in the strong external field from a position close to the wire to the anode. Due to the displacement of electrons with respect to positive ions, a polarization space charge field $E_{c}$ that can be as high as $100 \mathrm{kV} \mathrm{cm}^{-1}$ arises. ${ }^{77}$ Thus, the net electric field is weakened in the direction of the anode by the reverse space charge field that opposes the external electric field, and hence is strengthened in

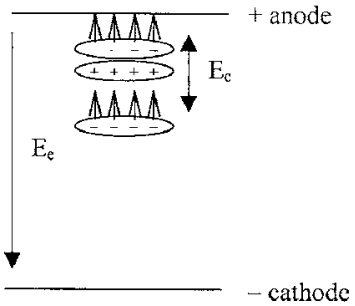

(a) streamer initiation

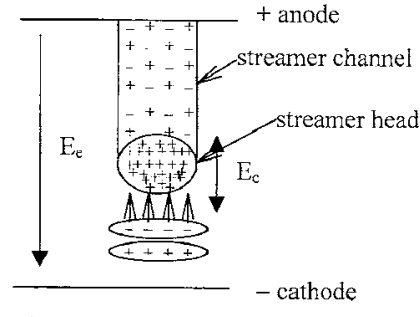

(b) streamer propagation
FIG. 7. Schematic diagram showing formation and development of streamer. 
TABLE V. Basic parameters for streamer discharge of nonthermal plasma at atmospheric pressure and ambient temperature.

\begin{tabular}{|c|c|c|c|c|}
\hline Item & Streamer head & Ref. & Streamer channel & Ref. \\
\hline Electron concentration & $10^{14}-10^{15} \mathrm{~cm}^{-3}$ & $\begin{array}{c}\text { Williams and } \\
\text { Peterkin (Ref. 79) }\end{array}$ & $\cdots$ & $\cdots$ \\
\hline Electrical resistance & $\cdots$ & $\cdots$ & $6 \mathrm{k} \Omega$ & $\begin{array}{c}\text { Williams and } \\
\text { Peterkin (Ref. 79) }\end{array}$ \\
\hline Electric field & $100 \mathrm{kV} \mathrm{cm}^{-1}$ & Kulikovsky (Ref. 77) & $\sim 5 \mathrm{kV} \mathrm{cm}^{-1}$ & $\begin{array}{c}\text { Morrow and } \\
\text { Lowke (Ref. 84) }\end{array}$ \\
\hline Electron drift velocity & $\sim 10^{8} \mathrm{~cm} \mathrm{~s}^{-1}$ & Namihira et al. (Ref. 85) & $\cdots$ & $\cdots$ \\
\hline Mean electron energy & $\sim 10 \mathrm{eV}$ & van Veldhuizen (Ref. 9) & $0.5-1 \mathrm{eV}$ & van Veldhuizen (Ref. 9) \\
\hline Diameter & $10^{-2} \mathrm{~cm}$ & Kulikovsky (Ref. 80) & $10^{-2}-10^{-1} \mathrm{~cm}$ & Kulikovsky (Ref. 86) \\
\hline $\begin{array}{l}\text { Total streamer volume } \\
\text { fraction }\end{array}$ & $\cdots$ & $\cdots$ & $10^{-4}-10^{-3}$ & van Veldhuizen (Ref. 9) \\
\hline Streamer density & $\cdots$ & $\cdots$ & $\leqslant 25$ streamers $/ \mathrm{mm}$ & Simek et al. (Ref. 87) \\
\hline
\end{tabular}

the direction of the cathode. This leads to further ionization of gas near the space charge in the direction of the cathode. This way, the streamer propagates from the anode to the cathode, while electron drift is in the reverse direction. The streamer tip is called the streamer head (ionization region), while the streamer tail is called the streamer channel (electron drift region), ${ }^{78}$ as shown in Fig. 7.

The streamer dynamics have been extensively studied both theoretically and experimentally. The basic parameters of streamer dynamics, $97,79,80$ are summarized in Table V. The following conclusions can be drawn from these parameters.

(1) The degree of ionization in the streamer is low. The electron concentration in the streamer head is $10^{14}-10^{15} \mathrm{e} \mathrm{cm}^{-3}$, corresponding to $\sim 15 \mathrm{ppm}$ at $300 \mathrm{~K}$ and $141 \mathrm{kPa}$ at the upper limit.

(2) The major electron collision reactions occur in the streamer head. The high electric field in the streamer head accelerates the electrons from the ionized gas. The mean electron energy in the streamer head is $\sim 10 \mathrm{eV}$, which is high enough to initiate molecular dissociation and excitation, but not high enough to initiate ionization processes. The electron energy in the streamer channel is too low to contribute significantly to the excitation processes. 9

(3) The electron drift velocity in the streamer head is the streamer propagation velocity. The streamer velocity of $\sim 10^{8} \mathrm{~cm} \mathrm{~s}^{-1}$ across a $1-2 \mathrm{~cm}$ gap implies that the electrical discharge should be complete in 10-20 ns, which is consistent with our experimental data. ${ }^{1}$

(4) The streamer diameter is small, and hence the total volume fraction of the streamers within the reactor volume is low.

Because of the low degree of ionization, the probability of direct electron-ion collision reactions is small compared to the probability of direct electron-molecule collision reactions in the streamer head. The direct electron-molecule collision reactions in the streamer head produce the radicals and excited states. The excited molecules with short lifetimes emit light when they transfer lower energy excited states, which is observed as fluorescence of the filamentlike streamer. The electron drift velocity $\left(\sim 10^{8} \mathrm{~cm} \mathrm{~s}^{-1}\right)$ in the streamer head is around three orders of magnitude higher than the thermal velocity (about $3.5 \times 10^{4} \mathrm{~cm} \mathrm{~s}^{-1}$ ) of the molecules, radicals, excited states, and positive ions. Due to the high streamer head velocity, essentially no reactions among molecules, radicals, excited states, and ions can occur in the streamer head. In other words, the streamer head passes and the streamer channel is formed before any significant reactions among molecules, radicals, excited states, and ions occur. Instead, the reactions among molecules, radicals, excited states, ions, and electrons occur in the streamer channel, where the electron velocity has been considerably reduced due to the energy transfer processes in the electron collision reactions. For example, all probable ion reactions in the streamer channel for $290 \mathrm{ppm} \mathrm{N}_{2} \mathrm{O}$ in argon are listed below.

$$
\begin{aligned}
& \mathrm{Ar}^{+}+\mathrm{Ar}+\mathrm{Ar} \rightarrow \mathrm{Ar}_{2}^{+}+\mathrm{Ar}, \\
& k=1.09 \times 10^{17} \mathrm{~cm}^{6} \mathrm{~mol}^{-2} \mathrm{~s}^{-1} \quad \text { (Ref. 51), } \\
& \mathrm{Ar}^{+}+\mathrm{N}_{2} \mathrm{O} \rightarrow \mathrm{N}_{2} \mathrm{O}^{+}+\mathrm{Ar}, \\
& k=1.75 \times 10^{14} \mathrm{~cm}^{3} \mathrm{~mol}^{-1} \mathrm{~s}^{-1} \quad \text { (Ref. 56), } \\
& e+\mathrm{Ar}^{+} \rightarrow \text { products, } \\
& k=1.81 \times 10^{17} \mathrm{~cm}^{3} \mathrm{~mol}^{-1} \mathrm{~s}^{-1} \quad \text { (Ref. 52), } \\
& e+\mathrm{Ar}_{2}^{+} \rightarrow \mathrm{products},, \quad \text { (Ref. 53), } \\
& k=5.48 \times 10^{17} \mathrm{~cm}^{3} \mathrm{~mol}^{-1} \mathrm{~s}^{-1} \quad \\
& \mathrm{Ar}_{2}^{+}+\mathrm{N}_{2} \mathrm{O} \rightarrow \mathrm{N}_{2} \mathrm{O}^{+}+2 \mathrm{Ar}, \\
& k=4.94 \times 10^{14} \mathrm{~cm}^{3} \mathrm{~mol}^{-1} \mathrm{~s}^{-1} \quad(\text { Ref. 57). }
\end{aligned}
$$

Using the calculated reactant concentrations and the rate constants listed above, the selectivities of $\mathrm{Ar}^{+}$consumption for reactions (12), (15), and (13) are estimated to be $69.4 \%$, $0.6 \%$, and $30.0 \%$, respectively. The selectivities of $\mathrm{Ar}_{2}{ }^{+}$consumption for reactions (14) and (18) are estimated to be $98.3 \%$ and $1.7 \%$, respectively. Therefore, the net selectivity of the $\mathrm{Ar}^{+}$contribution to charge transfer reaction with $\mathrm{N}_{2} \mathrm{O}$ is only about $1.8 \%$. Even at $\mathrm{NO}_{x}$ concentrations as high as $1000 \mathrm{ppm}$, only around $5.8 \%$ of $\mathrm{Ar}^{+}$and $\mathrm{Ar}_{2}{ }^{+}$contributes to 
charge transfer reactions with $\mathrm{N}_{2} \mathrm{O}$. In brief, the positive ions significantly contribute only to the recombination reactions with electrons to form the radicals and the excited states before any charge transfer reactions occur.

By contrast, since the drift velocity of electrons in the streamer head is very high, the electrons experience many collisions with gas molecules and produce much more radicals and excited states than ions. This has been demonstrated by Eliasson and Kogelschatz. ${ }^{71,81,82}$ They found that the concentrations of radicals and excited states is about two orders of magnitude higher than that of ions. These studies confirm that the major active species contributing to the $\mathrm{NO}_{x}$ conversion in nonthermal plasma are radicals and the excited states of atoms or molecules, and they support the conclusion of the present work that the contribution of ions to plasma reactions through charge transfer reactions is negligible.

\section{CONCLUSIONS}

On the basis of pulsed electrical discharge-induced optical emission spectra, the major active species produced from pulsed electrical discharge in argon are found to be the $\operatorname{Ar}(4 s)$ excited states. By contrast, $\mathrm{Ar}^{+}$and $\mathrm{N}_{2}^{+}$and their charge transfer reactions are found not to contribute to $\mathrm{NO}_{x}$ conversion in nonthermal argon plasma and nitrogen plasma, respectively, as determined from a detailed analysis of optical emission spectra induced by pulsed electrical discharge in argon, 290 ppm $\mathrm{N}_{2} \mathrm{O}$ in argon, $566 \mathrm{ppm} \mathrm{NO}$ in argon, and $408 \mathrm{ppm} \mathrm{N}_{2} \mathrm{O}$ in nitrogen. If positive ions are responsible for $\mathrm{NO}_{x}$ conversion in such mixtures, the optical emission of $\mathrm{NO}(B)$ should be observed due to the dissciative recombination reactions of $\mathrm{NO}_{2}^{+}$and $\mathrm{N}_{2} \mathrm{O}^{+}$. However, the optical emission of $\mathrm{NO}(B)$ is not observed. In general, charge transfer reactions are insignificant because (1) the cations formed from direct electron collision reactions are predominantly neutralized with electrons before any charge transfer reactions can occur and (2) concentrations of radicals in the streamer are far higher than that of cations, which results in negligible charged particle reactions. This means that neutral active species, such as atoms, molecular fragments, and excited molecules, are largely responsible for $\mathrm{NO}_{x}$ conversion in nonthermal plasma.

\section{ACKNOWLEDGMENTS}

This work was funded by the Department of Defense (ARO-DAAD19-01-1-0488) and the National Science Foundation (CTS-9810040 and CTS-0078700). The matching support was provided by the Research Office, University of Wyoming. The authors gratefully acknowledge experimental assistance provided by Dr. X. Hu, S. V. B. Janardhan Garikipati, Dr. S. Legowski, and R. Borgialli.

${ }^{1}$ X. Hu, G.-B. Zhao, J.-J. Zhang, L. Wang, and M. Radosz, Ind. Eng. Chem. Res. 43, 7456 (2004).

${ }^{2}$ G.-B. Zhao, S. V. B. J. Garikipati, X. Hu, M. D. Argyle, and M. Radosz, Chem. Eng. Sci. 60, 1927 (2005).

${ }^{3}$ G.-B. Zhao, S. V. B. J. Garikipati, X. Hu, M. D. Argyle, and M. Radosz, AIChE J. 51, 1813 (2005).

${ }^{4}$ J. B. A. Mitchell and C. Rebrion-Rowe, Int. Rev. Phys. Chem. 16, 201 (1997).

${ }^{5}$ T. Gougousi, M. F. Golde, and R. Johnsen, Chem. Phys. Lett. 265, 399
(1997).

${ }^{6}$ C. H. Sheehan and J.-P. St.-Maurice, J. Geophys. Res. 109, A03302 (2004).

${ }^{7}$ J. S. Chang, J. Aerosol Sci. 20, 1087 (1989).

${ }^{8}$ U. Kogelschatz, Plasma Chem. Plasma Process. 23, 1 (2003).

${ }^{9}$ E. M. van Veldhuizen, W. R. Rutgers, and V. A. Bityurin, Plasma Chem. Plasma Process. 16, 227 (1996).

${ }^{10}$ X. Hu, J.-J. Zhang, S. Mukhnahallipatna, J. Hamann, M. J. Biggs, and P. Agarwal, Fuel 82, 1675 (2003).

${ }^{11}$ G.-B. Zhao, X. Hu, M. D. Argyle, and M. Radosz, Ind. Eng. Chem. Res. 43, 5077 (2004).

${ }^{12}$ G.-B. Zhao, X. Hu, M. C. Yeung, O. A. Plumb, and M. Radosz, Ind. Eng. Chem. Res. 43, 2315 (2004).

${ }^{13}$ G.-B. Zhao, S. V. B. J. Garikipati, X. Hu, M. D. Argyle, and M. Radosz, AIChE J. 51, 1800 (2005).

${ }^{14}$ G.-B. Zhao, X. Hu, M. D. Argyle, and M. Radosz, Ind. Eng. Chem. Res. 44, 3925 (2005).

${ }^{15}$ G.-B. Zhao, X. Hu, M. D. Argyle, and M. Radosz, Ind. Eng. Chem. Res. 44, 3935 (2005).

${ }^{16}$ M. P. Skrzypkowski, R. Johnsen, R. E. Rosati, and M. F. Golde, Chem. Phys. 296, 23 (2004).

${ }^{17}$ H. Sun and H. Nakamura, J. Chem. Phys. 93, 6491 (1990).

${ }^{18}$ F. Hellberg, S. Rosén, R. Thomas, A. Neau, M. Larsson, A. Petrignani, and W. J. van der Zande, J. Chem. Phys. 118, 6250 (2003).

${ }^{19}$ S. Oddone, J. W. Sheldon, K. A. Hardy, and J. R. Peterson, Phys. Rev. A 56, 4737 (1997).

${ }^{20}$ J. R. Peterson et al., J. Chem. Phys. 108, 1978 (1998).

${ }^{21}$ A. Petrignani, W. J. van der Zande, P. C. Cosby, F. Hellberg, R. D. Thomas, and M. Larsson, J. Chem. Phys. 122, 014302 (2005).

${ }^{22}$ R. Peverall et al., J. Chem. Phys. 114, 6679 (2001).

${ }^{23}$ R. Johnsen, M. Skrzypkowski, T. Gougousi, R. Rosati, and M. F. Golde, in Proceedings of the American Chemical Society Symposium "Dissociative Recombination of Molecules with Electrons", edited by S. L. Guberman (Kluwer, New York, 2001), p. 25.

${ }^{24}$ R. Johnsen, M. Skrzypkowski, T. Gougousi, and M. F. Golde, in Dissociative Recombination: Theory, Experiment and Applications IV, Proceedings of the Conference, edited by M. Larsson, J. B. A. Mitchell, and I. F. Schneider (World Scientific, Singapore, 1999), p. 200.

${ }^{25}$ F. Tochikubo and T. H. Teich, Jpn. J. Appl. Phys., Part 1 39, 1343 (2000).

${ }^{26}$ J. Luque and D. R. Crosley, J. Chem. Phys. 112, 9411 (2000).

${ }^{27}$ J. Luque and D. R. Crosley, J. Quant. Spectrosc. Radiat. Transf. 53, 189 (1995).

${ }^{28}$ G.-B. Zhao, X. Hu, and M. Radosz, "Final Report-Investigations of a Pulsed Corona Reactor System Towards Remediation of Diesel Engine Exhaust, Prepared for The Army Research Office," Department of Chemical and Petroleum Engineering, University of Wyoming Reprot No. DODARMY1728, 2004 (unpublished).

${ }^{29}$ L. I. Berger, in CRC Handbook of Chemistry and Physics, edited by D. R. Lide (CRC, Boca Raton, FL, 2003), p. 15.

${ }^{30}$ R. C. Weast, M. J. Astle, and W. H. Beyer, CRC Handbook of Chemistry and Physics, 68th ed. (CRC, Boca Raton, FL, 1987).

${ }^{31}$ E. M. van Veldhuizen and W. R. Rutgers, J. Phys. D 35, 2169 (2002).

${ }^{32}$ A. Bultel, B. van Ootegem, A. Bourdon, and P. Vervisch, Phys. Rev. E 65, 046406/1 (2002).

${ }^{33}$ G.-B. Zhao, X. Hu, O. A. Plumb, and M. Radosz, Energy Fuels 18, 1522 (2004).

${ }^{34}$ R. Payling, D. G. Jones, and A. Bengtson, Glow Discharge Optical Emission Spectrometry (Wiley, Chichester, 1997), p. 440.

${ }^{35}$ X. Hu, G.-B. Zhao, S. V. B. J. Garikipati, K. Nicholas, S. F. Legowski, and M. Radosz, Plasma Chem. Plasma Process. 25, 351 (2005).

${ }^{36}$ G. Inoue, D. W. Setser, and N. Sadeghi, J. Chem. Phys. 76, 977 (1982).

${ }^{37}$ W. Whaling, W. H. C. Anderson, M. T. Carle, J. W. Brault, and H. A. Zarem, J. Res. Natl. Inst. Stand. Technol. 107, 149 (2002).

${ }^{38}$ R. S. F. Chang and D. W. Setser, J. Chem. Phys. 69, 3885 (1978).

${ }^{39}$ W. L. Wiese, J. W. Brault, K. Danzmann, V. Helbig, and M. Kock, Phys. Rev. A 39, 2461 (1989).

${ }^{40}$ K. Kano and H. Akatsuka, Phys. Rev. E 65, 056404/1 (2002).

${ }^{41}$ J. W. Keto and C.-Y. Kuo, J. Chem. Phys. 74, 6188 (1981).

${ }^{42}$ N. Sadeghi, D. W. Setser, A. Francis, U. Czarnetzki, and H. F. Döbele, J. Chem. Phys. 115, 3144 (2001).

${ }^{43}$ K. Tachibana, Phys. Rev. A 34, 1007 (1986).

${ }^{44}$ J. H. Kolts and D. W. Setser, J. Chem. Phys. 68, 4848 (1978).

${ }^{45}$ P. Moutard, P. Laporte, J.-L. Subtil, N. Damany, and H. Damany, J. Chem. Phys. 87, 4576 (1987). 
${ }^{46}$ N. E. Small-Warren and L.-Y. C. Chiu, Phys. Rev. A 11, 1777 (1975).

${ }^{47}$ H. Katori and F. Shimizu, Phys. Rev. Lett. 70, 3545 (1993).

${ }^{48}$ E. Ellis and N. D. Twiddy, J. Phys. B 2, 1366 (1969).

${ }^{49}$ J. B. Boffard, G. A. Piech, M. F. Gehrke, L. W. Anderson, and C. C. Lin, Phys. Rev. A 59, 2749 (1999).

${ }^{50}$ B. M. Penetrante et al., Appl. Phys. Lett. 68, 3719 (1996).

${ }^{51}$ R. Johnsen, A. Chen, and M. A. Biondi, J. Chem. Phys. 73, 1717 (1980).

${ }^{52}$ Z. Z. Su, K. Ito, K. Takashima, S. Katsura, K. Onda, and A. Mizuno, J. Phys. D 35, 3192 (2002)

${ }^{53}$ X. K. Hu, J. B. A. Mitchell, and R. H. Lipson, Phys. Rev. A 62, 052712/1 (2000).

${ }^{54}$ Y.-J. Shiu and M. A. Biondi, Phys. Rev. A 17, 868 (1978).

${ }^{55}$ C. Y. Kuo and J. W. Keto, J. Chem. Phys. 78, 1851 (1983).

${ }^{56}$ V. G. Anicich, J. Phys. Chem. Ref. Data 22, 1469 (1993).

${ }^{57}$ R. J. Shul, B. L. Upschulte, R. Passarella, R. G. Keesee, and J. A. W. Castleman, J. Phys. Chem. 91, 2556 (1987).

${ }^{58}$ R. J. Shul, R. Passarella, X. L. Yang, R. G. Keesee, and J. A. W. Castleman, J. Chem. Phys. 87, 1630 (1987).

${ }^{59}$ R. W. B. Pearse and A. G. Gaydon, The Identification of Molecular Spectra, 4th ed. (Wiley, London, 1976).

${ }^{60}$ J. Eloranta, K. Vaskonen, H. Hakkanen, T. Kiljunen, and H. Kunttu, J. Chem. Phys. 109, 7784 (1998).

${ }^{61}$ J. Luque and D. R. Crosley, J. Chem. Phys. 100, 7340 (1994).

${ }^{62}$ E. S. Hwang, J. Lacoursiere, R. A. Copeland, and T. G. Slanger, J. Chem. Phys. 107, 4522 (1997).

${ }^{63}$ R. A. Copeland, M. J. Dyer, H. I. Bloemink, and T. G. Slanger, J. Chem. Phys. 107, 2257 (1997).

${ }^{64}$ G. A. Raiche and D. R. Crosley, J. Chem. Phys. 92, 5211 (1990).

${ }^{65}$ I. S. McDermid and J. B. Laudenslager, J. Quant. Spectrosc. Radiat.
Transf. 27, 483 (1982).

${ }^{66}$ K. T. Wu, J. Phys. Chem. 92, 2657 (1988).

${ }^{67}$ N. Sadeghi, M. Cheaib, and D. W. Setser, J. Chem. Phys. 90, 219 (1989).

${ }^{68}$ A. Lofthus and P. H. Krupenie, J. Phys. Chem. Ref. Data 6, 113 (1977).

${ }^{69}$ L. G. Piper, G. E. Caledonia, and J. P. Kennealy, J. Chem. Phys. 75, 2847 (1981).

${ }^{70}$ J. T. Herron, J. Phys. Chem. Ref. Data 28, 1453 (1999).

${ }^{71}$ B. Eliasson and U. Kogelschatz, IEEE Trans. Plasma Sci. 19, 1063 (1991).

${ }^{72}$ L. B. Loeb and J. M. Meek, J. Appl. Phys. 11, 438 (1940).

${ }^{73}$ L. B. Loeb and J. M. Meek, J. Appl. Phys. 11, 459 (1940).

${ }^{74}$ R. S. Sigmond, J. Appl. Phys. 56, 1355 (1984).

${ }^{75}$ J. E. Jones, J. Dupuy, G. O. S. Schreiber, and R. T. Waters, J. Phys. D 21, 322 (1988)

${ }^{76}$ R. R. Ruan, W. Han, A. Ning, P. L. Chen, P. R. Goodrich, and R. Zhang, J. Adv. Oxid. Technol. 4, 328 (1999).

${ }^{77}$ A. A. Kulikovsky, IEEE Trans. Plasma Sci. 26, 1339 (1998).

${ }^{78}$ R. Gasparik, S. Ihara, C. Yamabe, and S. Satoh, Jpn. J. Appl. Phys., Part 1 39, 306 (2000).

${ }^{79}$ P. F. Williams and F. E. Peterkin, J. Appl. Phys. 66, 4163 (1989).

${ }^{80}$ A. A. Kulikovsky, J. Phys. D 28, 2483 (1995).

${ }^{81}$ B. Eliasson and U. Kogelschatz, J. Phys. B 19, 1241 (1986).

${ }^{82}$ B. Eliasson and U. Kogelschatz, IEEE Trans. Plasma Sci. 19, 309 (1991).

${ }^{83}$ M. J. Kiik, P. Dubé, and B. P. Stoicheff, J. Chem. Phys. 102, 2351 (1995).

${ }^{84}$ R. Morrow and J. J. Lowke, J. Phys. D 30, 614 (1997).

${ }^{85}$ T. Namihira, D. Wang, S. Katsuki, R. Hackam, and H. Akiyama, IEEE Trans. Plasma Sci. 31, 1091 (2003).

${ }^{86}$ A. A. Kulikovsky, J. Phys. D 30, 441 (1997).

${ }^{87}$ M. Simek, V. Babicky, M. Clupek, S. DeBenedictis, G. Dilecce, and P. Sunka, J. Phys. D 31, 2591 (1998). 
Journal of Applied Physics is copyrighted by the American Institute of Physics (AIP). Redistribution of journal material is subject to the AIP online journal license and/or AIP copyright. For more information, see http://ojps.aip.org/japo/japcr/jsp 